\title{
Review Article \\ Structure-Based Drug Design for Cytochrome P450 Family 1 Inhibitors
}

\author{
Zbigniew Dutkiewicz ${ }^{1}{ }^{1}$ and Renata Mikstacka ${ }^{2}$ \\ ${ }^{1}$ Department of Chemical Technology of Drugs, Poznań University of Medical Sciences, \\ Grunwaldzka 6, 60-780 Poznań, Poland \\ ${ }^{2}$ Department of Inorganic and Analytical Chemistry, Ludwik Rydygier Collegium Medicum, \\ Nicolaus Copernicus University in Toruń, Dr A. Jurasza 2, 85-089 Bydgoszcz, Poland \\ Correspondence should be addressed to Zbigniew Dutkiewicz; zdutkie@ump.edu.pl
}

Received 28 February 2018; Revised 17 May 2018; Accepted 20 June 2018; Published 25 July 2018

Academic Editor: Albrecht Messerschmidt

Copyright () 2018 Zbigniew Dutkiewicz and Renata Mikstacka. This is an open access article distributed under the Creative Commons Attribution License, which permits unrestricted use, distribution, and reproduction in any medium, provided the original work is properly cited.

\begin{abstract}
Cytochromes P450 are a class of metalloproteins which are responsible for electron transfer in a wide spectrum of reactions including metabolic biotransformation of endogenous and exogenous substrates. The superfamily of cytochromes P450 consists of families and subfamilies which are characterized by a specific structure and substrate specificity. Cytochromes P450 family 1 (CYP1s) play a distinctive role in the metabolism of drugs and chemical procarcinogens. In recent decades, these hemoproteins have been intensively studied with the use of computational methods which have been recently developed remarkably to be used in the process of drug design by the virtual screening of compounds in order to find agents with desired properties. Moreover, the molecular modeling of proteins and ligand docking to their active sites provide an insight into the mechanism of enzyme action and enable us to predict the sites of drug metabolism. The review presents the current status of knowledge about the use of the computational approach in studies of ligand-enzyme interactions for CYP1s. Research on the metabolism of substrates and inhibitors of CYP1s and on the selectivity of their action is particularly valuable from the viewpoint of cancer chemoprevention, chemotherapy, and drug-drug interactions.
\end{abstract}

\section{Introduction}

In the past decade, an interest in the use of computational methods in preclinical drug discovery has been continuously growing. Structure-based drug design (SBDD) became possible due to the availability of X-ray structures of receptors and the development of molecular modeling methods. The combined techniques employed in a drug discovery with respect to numerous receptors are still being improved and are becoming of better and better quality. There are thorough reviews of the actual possibilities of and prospects for using computational methods in drug design [1-5]. The present review is devoted to studies on cytochrome P450 family 1 (CYP1), an important family of enzymes responsible for drug metabolism and procarcinogen activation, with the use of molecular docking and molecular dynamics simulations. In some respects, family 1 of cytochromes $\mathrm{P} 450$ is exceptional. It comprises two isozymes, CYP1A1 and CYP1A2, of a great similarity and a third, more distinctive CYP1B1, which displays overlapping substrate specificity with the other members of the family. These three enzymes possessing relatively small binding cavities are valuable objects for comparative studies of enzymatic catalysis and ligand-enzyme interactions with the use of computational methods.

Cytochromes P450 (CYPs) are a superfamily of constitutive and inducible enzymes-hemoproteins-responsible for the oxidative metabolism of various xenobiotics and bioactive endogenous compounds. At present, 57 human genes of cytochromes P450 are known; they demonstrate a significant interindividual genetic variability [6]. On the basis of structural homology, CYPs may be assigned to the same family if they share not less than $40 \%$ of the amino acid sequence identity. Isoforms showing more than $55 \%$ sequence identity belong to the same subfamily. Family 1 (CYP1) comprises three isoforms: CYP1A1, CYP1A2, and CYP1B1. The amino acid sequence of CYP1A2 is $72 \%$ identical to that 
of CYP1A1, while CYP1B1 has lower amino acid sequence identity with both CYP1A1 (38\%) and CYP1A2 (37\%). Despite that, CYP1B1 is qualified as a CYP1 member on the basis of similar substrate specificity and the common induction of CYP1s by the aryl hydrocarbon receptor (AHR) [7].

CYP superfamily enzymes contain a heme prosthetic group catalyzing oxidation reactions and $\mathrm{N}$ - and $\mathrm{O}$-dealkylations of substrates. CYPs are diversified in respect to substrate specificity and inhibitor susceptibility. Family 1 of these enzymes/CYP1s is responsible for the phase I metabolism of endogenous and exogenous substrates. CYP1s participate in the oxidative metabolism of endogenous substances, such as bile acids, steroid hormones, and lipids, exogenous compounds, and numerous pharmaceuticals and compounds derived from environmental pollution. CYP1s metabolize potential carcinogens: aryl hydrocarbons, aromatic amines, heterocyclic aromatic amines, and heterocyclic amines. CYP1s play a pivotal role in procarcinogen activation catalyzing metabolism of $66 \%$ of potential carcinogens [8]. The biotransformation of procarcinogens leads to the formation of mutagenic compounds, which form adducts with nucleic bases, responsible for the initiation of carcinogenesis.

CYP1B1 plays a particularly important role in pathogenesis of hormone-induced cancers, being responsible for metabolism of 17-alpha-estradiol (E2) to highly mutagenic and carcinogenic 4-hydroxy-E2 [9]. 4-Hydroxy-E2 and other products of E2 metabolism-quinones and semiquinones-exhibit genotoxic activity by forming adducts with nucleic acids [10]. Recently, CYP1B1's role in cancer progression and metastasis was reported [11]. CYP1A1 and CYP1B1 are targets of anticancer agents because of their overexpression in tumor cells compared to their normal counterparts $[12,13]$. They may be used as a marker/tumor antigen in therapeutic strategies [14]. Overexpressed CYP1A1 or CYP1B1 in target tissues may play a doublesided role: they may activate prodrugs to their therapeutic forms, and on the contrary, they metabolize chemotherapeutics to their inactive forms. Inhibitors of CYP1B1 activity are used in mechanistic studies of drug metabolism [15].

Multidrug resistance caused by an efficient metabolism of chemotherapeutics catalyzed by CYP1A1 and CYP1B1 is a crucial problem in cancer chemotherapy. Moreover, interand intraspecies variability of CYP structures results in unique profiles of enzyme activities, which influence the therapeutic action of drugs metabolized by CYPs. The modeling of unique CYP structures may help to explain individual variation in response to drugs. To stop the inactivation of chemotherapeutics and to avoid drug resistance, the use of CYP1s inhibitors is proposed $[9,14-16]$.

The expression of CYP1 isoenzymes is tissue specific [17]. CYP1A 1 is an inducible enzyme that occurs in the lungs and the trachea. Its induction is dependent on the presence of pollutants in the environment. CYP1A2 is a hepatic constitutive form of the enzyme that is responsible for drug metabolism in the liver. CYP1B1 occurs in the majority of extrahepatic tissues. A high level of CYP1B1 is observed in the bone marrow, kidney, spleen, thyroid gland, and reproductive tissues such as the uterus or prostate and mammary glands [17].

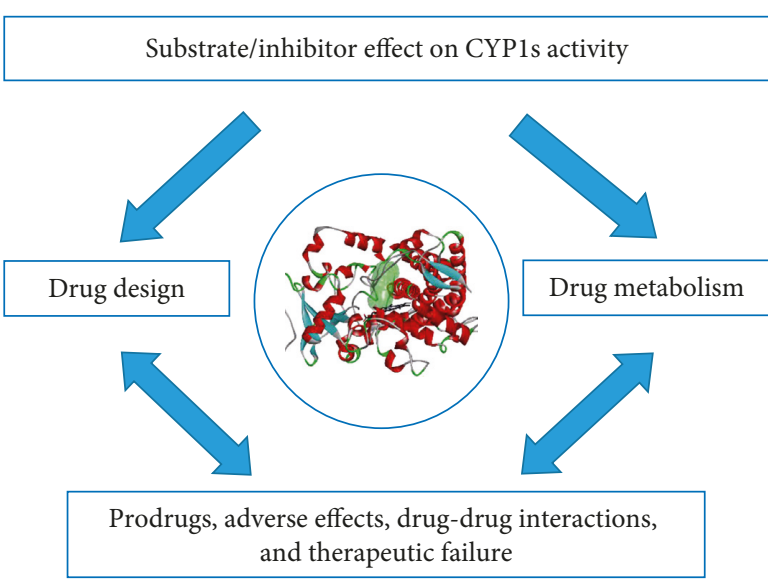

FIGURE 1: Relevance of CYP1 structure-activity relationship studies.

A focus on CYPs, in particular on CYP1s, arises from the role they play in the activation of procarcinogens. CYPs involved in the initiation of carcinogenesis have become the targets for anticancer strategy $[18,19]$. One of the prophylactic actions is chemoprevention, which was defined as a prevention, inhibition, or reversal of carcinogenesis with the use of compounds of natural origin, their derivatives, or synthetic compounds [20]. The inhibition of CYP1A1 and CYP1B1 activities by natural compounds present in human diet constitutes one of the chemopreventive strategies [21].

In the past, the interactions between cytochromes P450 (CYPs) and their ligands have been investigated on the basis of the homology models of cytochrome P450 isozymes [22-24]. The homology models of CYPs had been used until the crystallographic structures of CYP1A1, CYP1A2, and CYP1B1 were determined and described [25-27]. Now, the crystal structures of CYP1s are available in the Protein Data Bank (PDB, http://www.rcsb.org/pdb/home/home.do), which greatly facilitates the progress of hit identifications.

The computational approach in structure-activity relationship studies is conducted with the aim of determining the site of metabolism of drugs and prodrugs and explaining the mechanism of therapeutic failure, prodrug toxicity, and adverse effects (Figure 1). In computational-aided drug design at the "hit-to-lead" stage, two different approaches are used: the structure-based (or receptor-based) drug design (SBDD) and the ligand-based drug design (LBDD) in relation to the known structure of a receptor or a ligand.

This review summarizes in silico studies and the studies that combine investigations in vitro with a computational approach to CYP family 1 enzymes as targets for the inhibitory activity of ligands. In our review, we focused on the SBDD concerning CYP1 family enzymes. We surveyed the studies of interactions of lead compounds with CYP1A1, CYP1A2, and CYP1B1. We also discussed the studies focused on the search of compounds: substrates and inhibitors, which display selective and potent molecular interactions with individual isozymes.

\section{Structures of CYP1 Family Members}

2.1. CYP1A1. Before the structure of human CYP1A1 was determined, most reports concerning CYP1A1 were 
TABLE 1: The summary of studies on CYP1-ligand interactions.

\begin{tabular}{|c|c|c|c|c|}
\hline Cytochrome P450 & Ligand & Methods & Notes & References \\
\hline \multicolumn{5}{|c|}{ CYP1A1 and other cytochromes } \\
\hline & Aromatic amines, heterocyclic & & & \\
\hline CYP1A1 and & $\begin{array}{l}\text { amines, aromatic hydrocarbons } \\
(\text { benzo }(a)\end{array}$ & Homology modeling based on the & Human, mouse, rabbit, & \\
\hline CYP1A2 & $\begin{array}{l}\text { pyrenemethylcholantrene), } \\
\text { phenacetin, furafylline, and } \\
\text { 7-methoxyresorufin }\end{array}$ & CYP102 crystal structure & and trout CYP sequences & {$[22]$} \\
\hline CYP1A1 & $\begin{array}{l}\text { 7-Ethoxyresorufin, } \\
\text { 7-methoxyresorufin, and benzo }[a] \\
\text { pyrene }\end{array}$ & Homology modeling & & [28] \\
\hline $\begin{array}{l}\text { CYP1A1, CYP1A2, } \\
\text { and CYP1B1 }\end{array}$ & Rutaecarpine and its derivatives & Homology modeling & & {$[29]$} \\
\hline CYP1A1 & $\begin{array}{l}\text { Arachidonic acid and } \\
\text { eicosopentaenoic acid }\end{array}$ & Homology modeling & $\begin{array}{l}\text { Molecular docking } \\
\text { explains regiospecificity } \\
\text { of metabolism }\end{array}$ & {$[30]$} \\
\hline $\begin{array}{l}\text { CYP1A1 and } \\
\text { CYP1A2 }\end{array}$ & $\begin{array}{l}\text { 7-Methoxyresorufin and } \\
\text { 7-ethoxyresorufin }\end{array}$ & Homology modeling & $\begin{array}{c}\text { Active site mutations in } \\
\text { human CYP1A1 and } \\
\text { CYP1A2 }\end{array}$ & {$[31]$} \\
\hline $\begin{array}{l}\text { CYP1A1 and } \\
\text { CYP1A2 }\end{array}$ & Dietary flavonoids & Homology modeling & & {$[32]$} \\
\hline CYP1A1 & $\begin{array}{c}\mathrm{B}[a] \mathrm{P}, \mathrm{B}[a] \mathrm{P}-7 R, 8 R \text {-dihydrodiol, } \mathrm{B} \\
{[a] \mathrm{P}-7 S, 8 S \text {-dihydrodiol, }} \\
\text { eicosapentaenoate, and arachidonate }\end{array}$ & Homology modeling & Regioselectivity & {$[33]$} \\
\hline CYP1A1 & Ethoxyresorufin & Homology modeling & & {$[34]$} \\
\hline CYP1A1 & $\mathrm{B}[a] \mathrm{P}$ & $\begin{array}{l}\text { Wild-type and exon } 6 \text { del CYP1A1 } \\
\text { homology models }\end{array}$ & & {$[35]$} \\
\hline $\begin{array}{l}\text { CYP1A1, CYP1A2, } \\
\text { and CYP1B1 }\end{array}$ & $\begin{array}{l}\text { Alkoxyl derivatives of } \\
\text { 7,8-dehydrorutaecarpine }\end{array}$ & $\begin{array}{l}\text { Homology models based on the } \\
\text { crystal structure of rabbit CYP2C } 5\end{array}$ & & {$[36]$} \\
\hline CYP1A1 & $\mathrm{B}[a] \mathrm{P}, \mathrm{TCB}$, and TCDD & $\begin{array}{l}\text { Rat, human, scup, and killifish } \\
\text { homology models }\end{array}$ & & {$[37]$} \\
\hline CYP1A1 & $\begin{array}{c}\text { Representative ligands: } \\
\alpha \text {-naphthoflavone and benzothiazole }\end{array}$ & Homology modeling & & {$[38]$} \\
\hline CYP1A1 and & & CYP1A2 crystal structure (PDB: & Distances of ligands to & \\
\hline $\begin{array}{l}\text { CYP1A2 (CYP2A6 } \\
\text { and CYP2B1) }\end{array}$ & Arylacetylenes & $\begin{array}{l}\text { 2HI4) and homology model of } \\
\text { CYP1A1 }\end{array}$ & $\begin{array}{l}\text { heme, } \mathrm{Fe} \text {, and Phe } \\
\text { residues were analyzed }\end{array}$ & {$[39]$} \\
\hline CYP1A1 & Benzoxazoles and benzothiazoles & $\begin{array}{l}\text { CoMFA, homology modeling, and } \\
\text { molecular docking }\end{array}$ & & {$[40]$} \\
\hline $\begin{array}{l}\text { CYP1A1, CYP1A2, } \\
\text { and CYP1B1 } \\
\text { (CYP2C9 and } \\
\text { CYP3A4) }\end{array}$ & 33 flavonoid derivatives & $\begin{array}{l}\text { PDB: } 2 \mathrm{HI} 4 \text { and homology models of } \\
\text { CYP1A1 and CYP1B1 }\end{array}$ & $\begin{array}{l}\text { Hydroxyl and methoxy } \\
\text { derivatives of flavone } \\
\text { more potent as CYP } \\
\text { inhibitors }\end{array}$ & {$[41]$} \\
\hline $\begin{array}{l}\text { CYP1A1, CYP1A2, } \\
\text { and CYP1B1 }\end{array}$ & Methoxyflavonoids & $\begin{array}{l}\text { PDB: } 2 \mathrm{HI} 4 \text { and homology models of } \\
\text { CYP1A1 and CYP1B1 }\end{array}$ & $\begin{array}{l}\text { Important amino acid } \\
\text { residues }\end{array}$ & {$[42]$} \\
\hline $\begin{array}{l}\text { CYP1A1 and } \\
\text { CYP2B1 }\end{array}$ & $\begin{array}{l}p \text {-Aminophenol-succinic acid } \\
\text { derivatives (acetylcholinesterase } \\
\text { inhibitors) }\end{array}$ & $\begin{array}{l}\text { Homology modeling of rat CYPs } \\
\text { based on structures of CYP1A2 and } \\
\text { CYP3A4 and molecular dynamics }\end{array}$ & $\begin{array}{l}\text { Biological experiments } \\
\text { on rat microsomes } \\
\text { induced with 5,6- } \\
\text { benzoflavone and } \\
\text { phenobarbital }\end{array}$ & {$[43]$} \\
\hline $\begin{array}{l}\text { CYP1A1, CYP1A2, } \\
\text { and CYP1B1 }\end{array}$ & $17-\beta$-Estradiol & $\begin{array}{l}\text { PDB: } 2 \mathrm{HI} 4 \text { and homology models of } \\
\text { CYP1A1 and CYP1B1 }\end{array}$ & $\begin{array}{l}\text { Important amino acid } \\
\text { residues }\end{array}$ & {$[44]$} \\
\hline CYP1A1 & $\begin{array}{c}3,3^{\prime}, 4,4^{\prime}, \\
\text { 5-Pentachlorobiphenyl }\end{array}$ & Homology modeling & $\begin{array}{l}\text { Rat and human } \\
\text { recombinant } \\
\text { microsomes }\end{array}$ & {$[45]$} \\
\hline $\begin{array}{l}\text { CYP1A1 and } \\
\text { CYP1B1 }\end{array}$ & Resveratrol and its derivatives & $\begin{array}{l}\text { Homology modeling based on } \\
\text { CYP1A2 crystal structure }\end{array}$ & & {$[46]$} \\
\hline $\begin{array}{l}\text { CYP1A1 and } \\
\text { CYP1B1 }\end{array}$ & Dietary flavonoids & $\begin{array}{l}\text { Homology models based on the } \\
\text { structure of CYP1A2 (PDB: } 2 \mathrm{HI} 4)\end{array}$ & & {$[47]$} \\
\hline
\end{tabular}


TABle 1: Continued.

\begin{tabular}{|c|c|c|c|c|}
\hline Cytochrome P450 & Ligand & Methods & Notes & References \\
\hline $\begin{array}{l}\text { CYP1A1 and } \\
\text { CYP1A2 (CYP1A6 } \\
\text { and CYP2B1) }\end{array}$ & Flavone propargyl ethers & $\begin{array}{c}\text { CYP1A2 crystal structure (PDB: } \\
\text { 2HI4) and homology model of } \\
\text { CYP1A1 }\end{array}$ & $\begin{array}{l}\text { Flavone propargyl ethers } \\
\text { are more potent } \\
\text { inhibitors of CYP1A1 } \\
\text { and CYP1A2 than the } \\
\text { parent hydroxy flavones }\end{array}$ & {$[48]$} \\
\hline $\begin{array}{l}\text { CYP1A1 and } \\
\text { CYP1A2 }\end{array}$ & Phenacetin and acetaminophen & $\begin{array}{c}\text { CYP1A2 crystal structure (PDB: } \\
\text { 2HI4) and homology model of } \\
\text { CYP1A1 }\end{array}$ & $\begin{array}{l}\text { Isoform-selective } \\
\text { metabolism }\end{array}$ & [49] \\
\hline $\begin{array}{l}\text { CYP1A1 and } \\
\text { CYP1B1 }\end{array}$ & Polycyclic aromatic hydrocarbons & Homology modeling & & {$[50]$} \\
\hline CYP1A1 & Sulforaphane & $\begin{array}{l}\text { The tertiary structure of CYP1A1 } \\
\text { was generated with the combination } \\
\text { methods of threading, ab initio } \\
\text { modeling, and structural refinement }\end{array}$ & $\begin{array}{l}\text { Sulforaphane failed to } \\
\text { reduce the genotoxic } \\
\text { effect of TCDD in yeast } \\
\text { cells }\end{array}$ & {$[51]$} \\
\hline CYP1A1 & $\begin{array}{l}\text { Pyrimidobenzothiazole } \\
\text { (NSC745689) }\end{array}$ & $\begin{array}{l}\text { Homology modeling and molecular } \\
\text { dynamics }\end{array}$ & & {$[52]$} \\
\hline $\begin{array}{l}\text { CYP1A1, CYP1A2, } \\
\text { and CYP1B1 } \\
\text { (CYP2A6 and } \\
\text { CYP2B1) }\end{array}$ & Pyranoflavones & & $\begin{array}{l}\text { Molecular surface } \\
\text { images generated from } \\
\text { UCSF Chimera }\end{array}$ & {$[53]$} \\
\hline $\begin{array}{l}\text { CYP1A1 and } \\
\text { CYP1A2 }\end{array}$ & Ethynylflavones & PDB: 4I8V and PDB: $2 \mathrm{HI} 4$ & $\begin{array}{l}\text { Selective inhibitory } \\
\text { activity toward CYP1A1 }\end{array}$ & {$[54]$} \\
\hline CYP1A1 & $\begin{array}{l}\text { Polychlorinated dibenzo-p-dioxins } \\
\text { and coplanar polychlorinated } \\
\text { biphenyls }\end{array}$ & Homology modeling & Rat and human CYP1A1 & {$[55]$} \\
\hline $\begin{array}{l}\text { CYP1A1, CYP1A2, } \\
\text { and CYP1B1 }\end{array}$ & Polymethoxystilbenes & $\begin{array}{l}\text { PDB: } 4 \mathrm{I} 8 \mathrm{~V}, \mathrm{PDB}: 2 \mathrm{HI} 4 \text {, and PDB: } \\
\text { 3PM0 }\end{array}$ & $\begin{array}{l}\text { Potent and selective } \\
\text { inhibitory activity of } \\
2,3^{\prime}, \\
4^{\prime} \text {-trimethoxy-trans- } \\
\text { stilbene }\end{array}$ & {$[56]$} \\
\hline $\begin{array}{l}\text { CYP1A1, CYP1A2, } \\
\text { and CYP1B1 }\end{array}$ & 30 drugs metabolized by CYPs & $\begin{array}{c}\text { PDB: } 4 \mathrm{I} 8 \mathrm{~V}, \mathrm{PDB}: 2 \mathrm{HI} 4 \text {, and PDB: } \\
\text { 3PM0 }\end{array}$ & MetaSite & {$[57]$} \\
\hline $\begin{array}{l}\text { CYP1A1 and } \\
\text { CYP1A2 }\end{array}$ & $\begin{array}{l}22 \text { aromatic hydrocarbons and } 3 \\
\text { fluorogenic alkoxyaryl compounds }\end{array}$ & PDB: 4I8V and PDB: $2 \mathrm{HI} 4$ & CYP1A variants & {$[58]$} \\
\hline $\begin{array}{l}\text { CYP1A1, CYP1A2, } \\
\text { and CYP1B1 }\end{array}$ & Alkoxyresorufins & Homology modeling & $\begin{array}{l}\text { Baikal seal and human } \\
\text { CYPs }\end{array}$ & {$[59]$} \\
\hline $\begin{array}{l}\text { CYP1A1, CYP1A2, } \\
\text { and CYP1B1 }\end{array}$ & $\begin{array}{l}\text { 5F-203, 5-aminoflavone, } \\
\text { 17- } \beta \text {-estradiol, melatonin, } \\
\text { debrisoquine, theophylline, } \\
\text { clozapine, and lidocaine }\end{array}$ & $\begin{array}{l}\text { PDB: 4I8V, PDB: } 2 \mathrm{HI} 4 \text {, and PDB: } \\
\text { 3PM0 }\end{array}$ & $\begin{array}{l}\text { Differences in substrate } \\
\text { specificity among CYPs }\end{array}$ & {$[60]$} \\
\hline CYP1A1 & $\begin{array}{l}\text { Naringenin and } \\
\text { dihydroxybergamottin }\end{array}$ & $\begin{array}{l}\text { Rat homology model, human PDB: } \\
4 \mathrm{I} 8 \mathrm{~V} \text {, and molecular dynamics }\end{array}$ & & {$[61]$} \\
\hline CYP1A1 & $\begin{array}{l}\text { Compounds selected by virtual } \\
\text { screening of databases }\end{array}$ & $\begin{array}{l}\text { Database screening, Hypo1; } \\
\text { metabolite prediction study, } \\
\text { MetaSite software; molecular } \\
\text { docking studies; and molecular } \\
\text { dynamics simulations }\end{array}$ & $\begin{array}{l}\text { Antiproliferative activity } \\
\text { on MDA-MB- } 435 \\
\text { human cells and two lead } \\
\text { compounds with } \\
\text { antitumor activity } \\
\text { against MDA-MB-435 } \\
\text { line }\end{array}$ & {$[62]$} \\
\hline $\begin{array}{l}\text { CYP1A1, CYP1A2, } \\
\text { and CYP1B1 }\end{array}$ & $\begin{array}{l}\text { Polymethoxy- and methylthio- } \\
\text { trans-stilbene derivatives }\end{array}$ & $\begin{array}{c}\text { PDB: } 4 \mathrm{I} 8 \mathrm{~V}, \mathrm{PDB}: 2 \mathrm{HI} 4 \text {, and PDB: } \\
\text { 3PM0 }\end{array}$ & & {$[63]$} \\
\hline \multicolumn{5}{|c|}{ CYP1A2 and other cytochromes } \\
\hline CYP1A2 & Caffeine and MeIQ & $\begin{array}{c}\text { Homology model based on CYP } \\
\text { BM3 crystal structure }\end{array}$ & & {$[64]$} \\
\hline $\begin{array}{l}\text { CYP1A2 (CYP2D6 } \\
\text { and CYP3A4) }\end{array}$ & Selected substrates & Homology modeling & $\begin{array}{l}\text { Substrate selectivity } \\
\text { studies }\end{array}$ & {$[65]$} \\
\hline CYP1A2 & 7-Methoxyresorufin & $\begin{array}{l}\text { Homology model based on the } \\
\text { crystal structure of CYP2C5 }\end{array}$ & $\begin{array}{l}\text { Hydrogen bonds and } \\
\pi-\pi \text { stacking with } \\
\text { Phe } 226\end{array}$ & {$[66]$} \\
\hline
\end{tabular}


TABle 1: Continued.

\begin{tabular}{|c|c|c|c|c|}
\hline Cytochrome P450 & Ligand & Methods & Notes & References \\
\hline $\begin{array}{l}\text { CYP1A2 (CYP2A6, } \\
\text { CYP2C9, CYP3A4, } \\
\text { and CYP2E1) }\end{array}$ & $\begin{array}{l}\text { Caffeine, theophylline, acetanilide, } \\
\text { phenacetin, 7-methoxycoumarin, } \\
\text { 7-ethoxycoumarin, 3-cyano-7'- } \\
\text { ethoxycoumarin, naproxen, tacrine, } \\
\text { amitriptyline, clozapine, and } \\
\text { 7-ethoxyresorufin }\end{array}$ & PDB: 2HI4 & $\begin{array}{l}\text { Regioselectivity } \\
\text { prediction of CYP1A2- } \\
\text { mediated metabolism }\end{array}$ & {$[67]$} \\
\hline CYP1A2 & $\begin{array}{l}\text { Methoxyresorufin and } \\
\text { ethoxyresorufin }\end{array}$ & $\begin{array}{l}\text { CYP1A2 homology model and } \\
\text { crystal structure PDB: } 2 \mathrm{HI} 4 \text { and } \\
\text { homology structures of CYP1A2 } \\
\text { mutants }\end{array}$ & & {$[68]$} \\
\hline CYP1A2 & Virtual screening of CYP1A2 ligands & $\begin{array}{l}\text { PDB: 2HI4 and automated docking } \\
\text { (Gold version 3.2) }\end{array}$ & $\begin{array}{l}\text { Prediction of the site of } \\
\text { metabolism }\end{array}$ & [69] \\
\hline CYP1A2 & $\begin{array}{l}\text { Structurally diverse CYP1A2 ligands } \\
\text { (substrates and inhibitors) }\end{array}$ & PDB: $2 \mathrm{HI} 4$ and molecular dynamics & $\begin{array}{l}\text { Versatility and plasticity } \\
\text { of the CYP1A2 active } \\
\text { site }\end{array}$ & {$[70]$} \\
\hline CYP1A2 (CYP2C9) & $\begin{array}{l}\text { Chrysin, 7,8-benzoflavone, } \\
\text { 7-hydroxyflavone, and warfarin }\end{array}$ & PDB: $2 \mathrm{HI} 4$ and molecular dynamics & & {$[71]$} \\
\hline CYP1A2 & Phenacetin & PDB: 2HI4 & $\begin{array}{l}\text { Wild-type and mutant } \\
\text { forms of enzyme }\end{array}$ & {$[72]$} \\
\hline CYP1A2 & $\begin{array}{l}\text { Virtual screening of } 971 \text { herb } \\
\text { compounds }\end{array}$ & $\begin{array}{l}\text { Pharmacophore searching and } \\
\text { docking procedure to CYP1A2 } \\
\text { crystal structure (PDB: } 2 \mathrm{HI} 4 \text { ) }\end{array}$ & Herb-drug interactions & {$[73]$} \\
\hline $\begin{array}{l}\text { CYP1A2 (CYP2A6, } \\
\text { CYP2C9, and } \\
\text { CYP2D6) }\end{array}$ & & PDB: 2HI4 and molecular dynamics & $\begin{array}{l}\text { Flexibility at normal and } \\
\text { high-pressure conditions } \\
\qquad(300 \mathrm{MPa})\end{array}$ & {$[74]$} \\
\hline $\begin{array}{l}\text { CYP1A2 and } \\
\text { CYP1B1 }\end{array}$ & Polymethoxy-trans-stilbenes & $\begin{array}{l}\text { PDB: } 2 \mathrm{HI} 4 \text { and homology model of } \\
\text { CYP1B1 }\end{array}$ & $\begin{array}{l}\text { Potent and selective } \\
\text { inhibitory activity of } \\
2,4,2^{\prime}, \\
6^{\prime} \text {-tetramethoxy-trans- } \\
\text { stilbene }\end{array}$ & {$[75]$} \\
\hline CYP1A2 & $\begin{array}{l}\text { 7,8-Benzoflavone, oroxylin, and } \\
\text { wogonin }\end{array}$ & $\begin{array}{l}\text { PDB: } 2 \mathrm{HI} 4 \text {, binding free energy } \\
\text { analysis with the MM-PBSL method, } \\
\text { and molecular dynamics }\end{array}$ & & {$[76]$} \\
\hline $\begin{array}{l}\text { CYP1A2 and } \\
\text { CYP1B1 }\end{array}$ & $\begin{array}{l}4^{\prime} \text {-Methylthio-trans-stilbene } \\
\text { derivatives }\end{array}$ & PDB: 2HI4 and PDB: 3PM0 & & {$[77]$} \\
\hline CYP1A2 & 7-Ethoxyresorufin & $\begin{array}{c}\text { PDB: 2HI4, ensemble docking, and } \\
\text { molecular dynamics }\end{array}$ & Phe186Leu mutation & [78] \\
\hline $\begin{array}{l}\text { CYP1A2 (CYP2C9, } \\
\text { CYP2D6, and } \\
\text { CYP3A })\end{array}$ & Kinase inhibitors & PDB: 2HI4 & Drug-drug interactions & {$[79]$} \\
\hline $\begin{array}{l}\text { CYP1A2 (CYP2A6, } \\
\text { CYP2C9, CYP3A4, } \\
\text { and CYP2E1) }\end{array}$ & Acetaminophen & $\begin{array}{l}\text { Large-scale 2D umbrella sampling, } \\
\text { PDB: } 2 \mathrm{HI} 4 \text {, and molecular dynamics }\end{array}$ & Regioselectivity & {$[80]$} \\
\hline CYP1A2 & & $\begin{array}{l}\text { The initial structure of wild-type } \\
\text { CYP1A2 (CYP1A2.1) constructed } \\
\text { from the CYP1A2 crystal structure } \\
\text { PDB: 2HI4, and CYP1A2 mutants } \\
\text { constructed from CYP1A2.1 refined } \\
\text { after molecular dynamics simulation }\end{array}$ & $\begin{array}{l}\text { Influence of amino acid } \\
\text { mutations on the 3D } \\
\text { structure and dynamic } \\
\text { properties of the enzyme }\end{array}$ & {$[81]$} \\
\hline \multicolumn{5}{|c|}{ CYP1B1 } \\
\hline CYP1B1 & $\begin{array}{l}\text { 17- } \beta \text {-Estradiol, } \alpha \text {-naphthoflavone, } \\
\text { 7-ethoxycoumarin, } \\
\text { 7-ethoxyresorufin, bufuralol, and } \\
\text { benzo }(a) \text { pyrene-7,8-diol }\end{array}$ & $\begin{array}{l}\text { Homology model based on the } \\
\text { structure of CYP2C5 }\end{array}$ & $\begin{array}{l}\text { Allelic variant effects on } \\
\text { metabolism }\end{array}$ & {$[82]$} \\
\hline CYP1B1 & $17-\beta$-Estradiol & $\begin{array}{l}\text { Molecular dynamics simulations of } \\
\text { homology-modeled structures }\end{array}$ & PCG-associated mutants & {$[83]$} \\
\hline CYP1B1 & 7,8-Benzoflavone derivatives & PDB: 3PM0; MOE docking program & $\begin{array}{l}\text { Inhibitors that eliminate } \\
\text { CYP1B1-mediated drug } \\
\text { resistance }\end{array}$ & {$[16]$} \\
\hline
\end{tabular}

B[a]P: benzo[a]pyrene; TCB: 2,3',4,4'-tetrachlorobiphenyl; TCDD: tetrachlorodibenzo- $p$-dioxin; PCG: primary congenital glaucoma. 


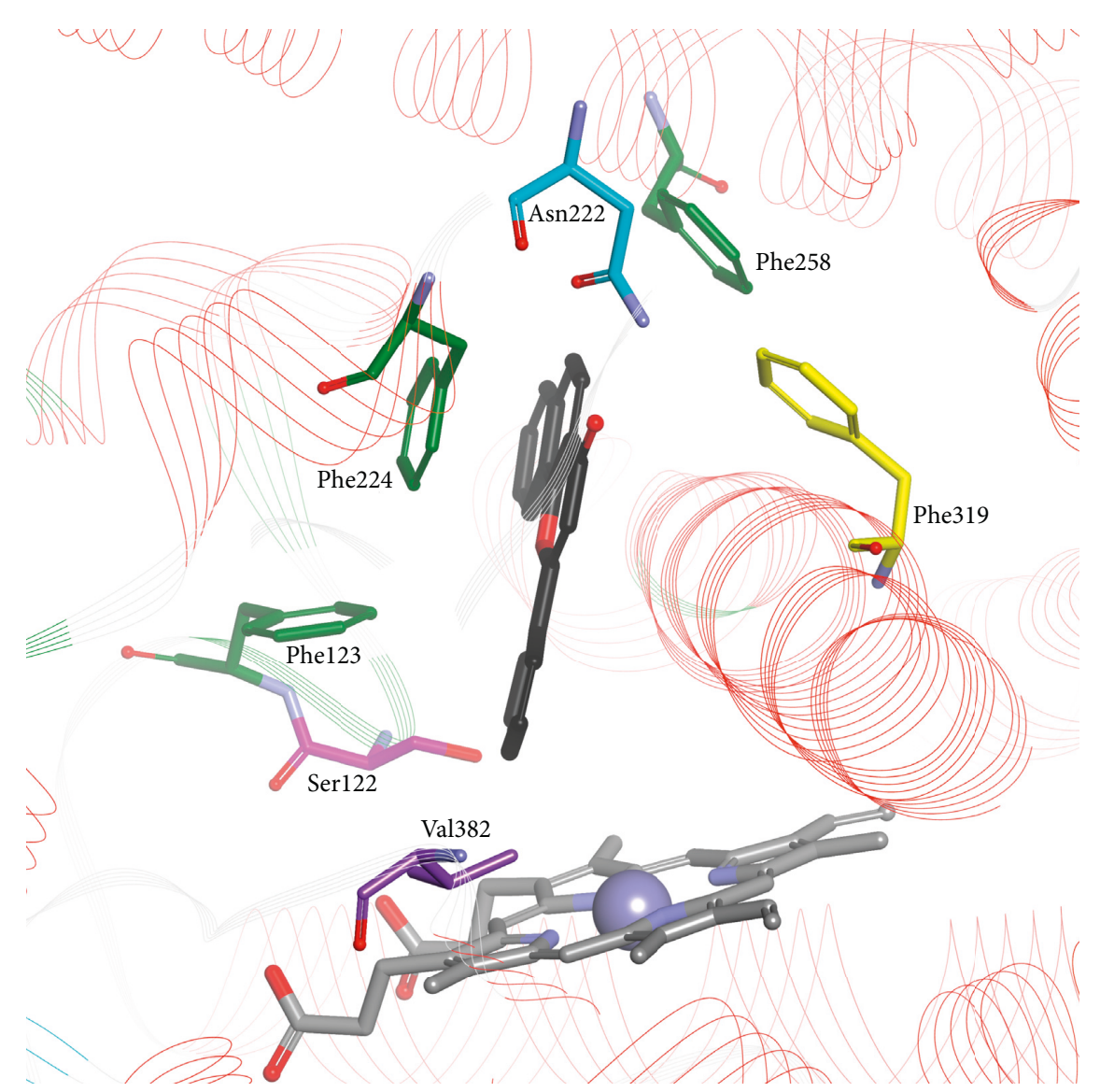

Figure 2: ANF bound in the active site of CYP1A1 (PDB ID: 4I8V). ANF: black carbon atoms; conserved phenylalanines 123, 224, and 258: light green; selected nonconserved residues: Ser122, Asn222, Phe319, and Val382.

performed on homology models (Table 1). In the1990s, homology models were based on crystal structures of bacterial enzymes. The first reports involved the CYP1A1 model based on the structure of bacterial CYP102 (CYP BM3) [22]. The disadvantage of this model was a low sequence homology between bacterial and eukaryotic CYPs. A better homology was achieved for the CYP1A1 constructed by Szklarz and Paulsen [28] with the use of mammalian CYP2C5, the first crystal structure of a microsomal CYP 2C5 from a rabbit [84]. Since 2007, the crystal CYP1A2 structure has been available, and the CYP1A1 homology model based on this template was constructed, achieving a better stereochemical quality [34].

The crystal 2.6 ̊̊ structure of human CYP1A1 (PDB: 4I8V; Figure 2) in complex with the inhibitor $\alpha$-naphthoflavone (ANF) was determined by Walsh and coworkers in 2013 as the last of the three members of the CYP1 family [25]. The overall CYP1A1 structure displays the typical cytochrome P450 fold with canonical helices $\mathrm{A}-\mathrm{L}$ and short $\mathrm{F}^{\prime}$ and $\mathrm{G}^{\prime}$ helices thought to be buried in the membrane and probably involved in enabling the access of hydrophobic ligands to the active site. A characteristic five-residue break in the middle of the $\mathrm{F}$ helix and lack of one of the four canonical $\beta$ sheets that occur in human P450 enzymes were also found in the CYP1A1 crystal structure [25].

Recently, the CYP1A1 structure was used in studies of interactions of the enzyme with a great number of CYP1A1 substrates and inhibitors summarized in Table 1, including phytochemicals, for example, dietary flavonoids [32, 41, 47]; drugs, for example, melatonin, debrisoquine, theophylline, clozapine, and carvedilol [57]; environmental pollutants, for example, aromatic hydrocarbons and their derivatives $[22,28,35,37,45,55]$; and natural and synthetic derivatives of trans-stilbene [25, 46, 63].

The CYP1A1 crystal structure was harnessed to identify new leads exhibiting CYP1A1-mediated anticancer activity [62]. The authors generated and validated a ligand-based pharmacophore model using a series of known anticancer compounds acting via CYP1A1. Selected compounds were subsequently subjected to pharmacokinetic screening, MetaSite screening, a molecular docking study, and a PAINS (pan-assay interference compounds) filter to refine the retrieved hits. Nine compounds capable of generating reactive metabolites and good interactions with CYP1A1 were selected for further studies in vitro. Two compounds showing a potent activity against the MDA-MB-435 cell line with $\mathrm{IC}_{50}<0.1 \mu \mathrm{M}$ and low toxicity to normal cells were selected. These compounds were metabolized by CYP1A1 to the $N$ hydroxylated products that are potential genotoxic agents and may be responsible for a toxic effect of parent compounds. A molecular dynamics simulation analysis was used to visualize the orientation of hit molecules in a CYP1A1 binding site cavity, which promotes bioactive metabolite formation by N-hydroxylation [62]. 


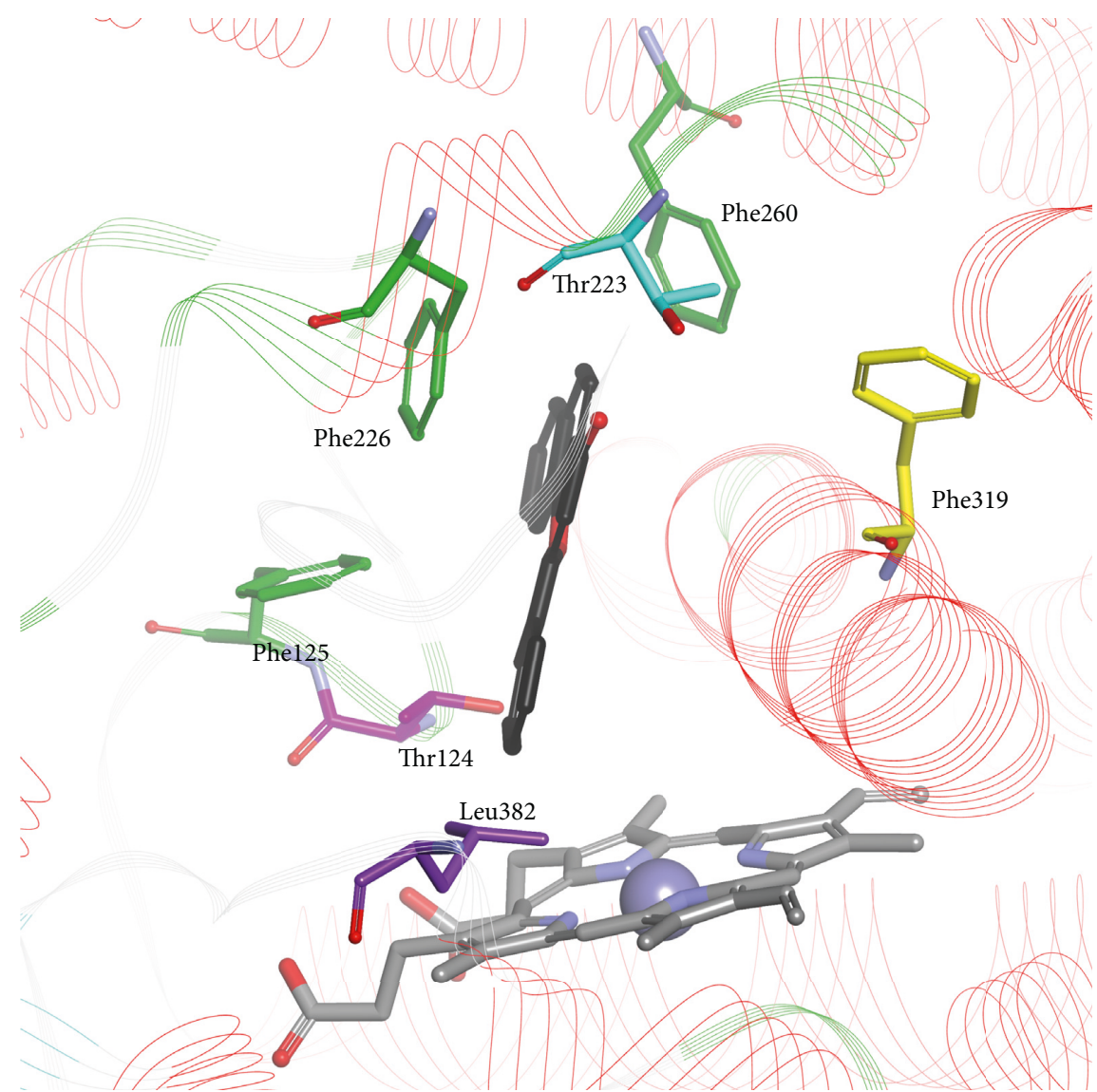

FIGURE 3: ANF bound in the active site of CYP1A2 (PDB ID: 2HI4). ANF: black carbon atoms; conserved phenylalanines 125, 226, and 260: light green; selected nonconserved residues: Thr124, Thr223, Phe319, and Leu382.

2.2. CYP1A2. The crystal structure of CYP1A2 (PDB: 2HI4; Figure 3) was published in 2007, becoming a template for other members of the CYP1 subfamily [26]. This structure had been employed in the homology modeling of CYP1A1 and CYP1B1 until their crystal structures were determined. Site-directed mutagenesis and homology modeling studies of Wang and Zhou [85] revealed a series of residues in the substrate recognition sites (SRSs) of CYP1A2 (Arg108, Thr124, Glu225, Phe226, Lys250, Arg251, Lys253, Asn312, Glu318, Thr319, Asp320, Thr321, Vall322, Leu382, Thr385, and Ile386), which have been shown to play important roles in ligand-enzyme binding.

In the studies of flexibility of human cytochrome P450 enzymes (CYP1A2, CYP2A6, CYP2C9, 2D6, and CYP3A4) with molecular dynamics in combination with UV/Vis and resonance Raman spectroscopy, the active site of CYP1A2 was described as small and rigid in contrast to CYP3A4, which displayed a greater flexibility and the highest substrate promiscuity [74].

The narrow and flat binding pocket of CYP1A2 determines the substrate specificity of the enzyme. Phenacetin, ANF, furafylline, caffeine, and 7-methoxyresorufin serve as standard CYP1A2 inhibitors. Drug metabolism prediction with the use of docking, molecular dynamics, and quantum chemical methods was a good option to screen a library for potential inhibitors and drug-drug interactions $[69,86]$. An efficient model for in silico screening was developed to identify CYP1A2 inhibitors in databases of herbal ingredients [73]. A rationale for these studies was herb-drug interactions. First, a pharmacophore model was constructed and validated. Then, the best pharmacophore model was chosen for a virtual screening of 989 herbal compounds. The hits (147 herbal compounds) were investigated through molecular docking and tested in vitro. Finally, 5 inhibitors of 18 candidate compounds were found to inhibit CYP1A2 activity. Molecular dynamics simulations provided an insight into the role of molecules of water in the enzyme active site. ANF forms the hydrogen bond with a water molecule, but during the simulations, different water molecules interact with ANF at different points of time [70].

Recently, more than 200 ns MD simulations were performed to investigate the role of water molecules in the active site of CYP1A2 complexed with 7-ethoxyresorufin and ANF [87]. Docking studies followed by MD simulations revealed that water molecules have an effect on hydrogen bond networks formed in the enzyme active site influencing the interactions of the substrate with amino acids in the enzyme active site. It appeared that water molecules were necessary for 7-ethoxyresorufin recognition, while for ligand recognition (ANF), water molecules were not required. The last conclusion is not consistent with the fact that, in the crystal structure of the CYP1A2 binding site (PDB: 2HI4), a water molecule is present. It is likely that the CYP1A2ANF-WAT complex, with the crystal water molecule, did not 


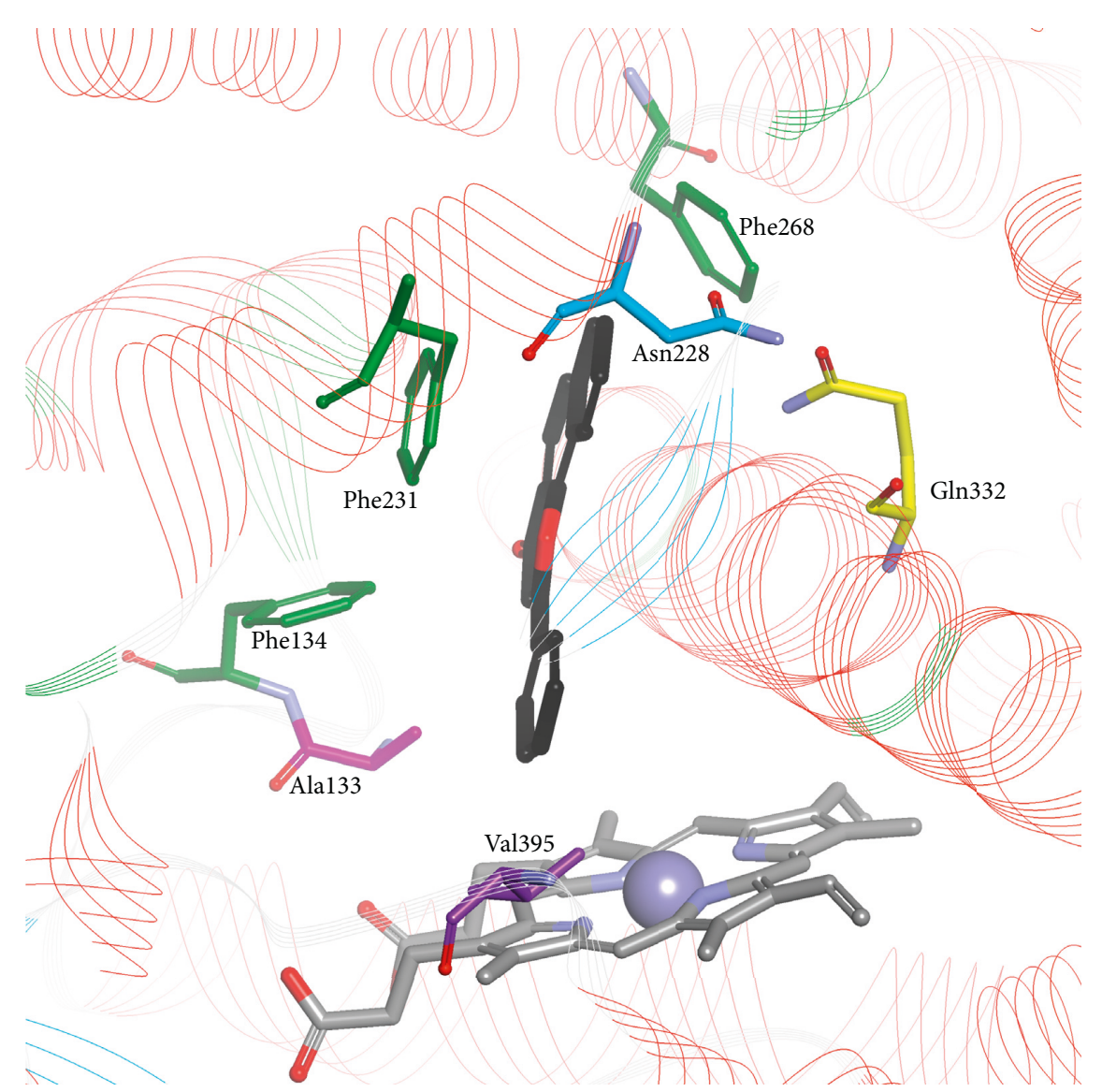

FIGURE 4: ANF bound in the active site of CYP1B1 (PDB ID: 3PM0). ANF: black carbon atoms; conserved phenylalanines 134, 231, and 268: light green; selected nonconserved residues: Ala133, Asn228, Gln332, and Val395.

reach equilibrium even during a longer (400 ns) simulation, which may be indicated by large fluctuations in RMSD for the ANF molecule, and the complex is in an intermediate state, between equilibrium and crystal structure.

2.3. CYP1B1. The crystallographic structure of CYP1B1 (PDB: 3PM0; Figure 4) was determined by Wang and coworkers [27] with ANF as a ligand bound in the active site cavity. Like the CYP1A subfamily, CYP1B1 has a narrow active site. However, the sequence divergence causes a different orientation of ANF in CYP1B1, CYP1A1, and CYP1A2. Amino acids that line the edges of the cavities modify the substrate and inhibitor binding to CYP1B1 and other CYPs. In the characteristic distortion of the helix F of CYP1B1 and CYP1A2, $\pi-\pi$ stacking interactions occur with Phe231 and Phe226, respectively. The amino acid residues Val395 and Ala133 determine the cavity shape in the vicinity of the heme. Val395 plays the role of Val382 in CYP1A1.

2.4. A Comparison of CYP1 Structures. A comparison of CYP1 family enzyme structures points to similarities and differences among the three active sites that determine their varied substrate specificities. The structures of all members of the CYP1 family were determined as complexes with ANF, making possible the comparison of ANF interactions in the active site cavities. ANF bound in the CYP1 cavities occupies the same plane adjacent to the heme and opposite to the I helix in each enzyme. The orientations of ANF in CYP1A1 and CYP1A2 are similar, whereas in CYP1B1, ANF is flipped by $180^{\circ}$ about the long axis of the ligand.

The most meaningful differences in the structure were listed and analyzed by Walsh et al. [25]. The residue at position 382 is known to be important in determining the functional differences between CYP1A1 and CYP1A2; mutations at this position have a significant impact on the catalytic efficiency of enzymes; the smaller 382 residue facilitates ligand placement in the enzyme cavity. In CYP1A1, the only interaction formed by ANF is $\pi-\pi$ stacking with Phe224 that is situated on the opposite side of I helix. In the CYP1A2 active site, there is a water molecule that forms hydrogen bonds with carbonyl groups of ANF and Gly316 [25]. A five-residue break in the CYP1A1 F helix has an effect on ligand binding, increasing the flexibility of the active site. The volumes of the active sites of CYP1A1, CYP1A2, and CYP1B1, which are 524, 375, and $398 \AA^{3}$, respectively [25-27], and crucial amino acid residues in the enzyme cavity determine the shape of the best-fitted ligands. A triangle with the side length of $9.3,8.7$, and $7.2 \AA$ was proposed as a contour of selective CYP1A2 inhibitors [53]. Moreover, CYP1A1 side chains of amino acid residues lining the active site are smaller in comparison to the corresponding residues in CYP1A2. For example, amino acid residues in the vicinity of the heme, Val382 in CYP1A1 and 
Val395 in CYP1B1, are replaced by the branched Leu382 in CYP1A2 narrowing the CYP1A2 cavity, which results in a lesser affinity of polymethoxystilbenes to CYP1A2 in comparison to CYP1A1 [63].

To investigate the active sites of CYP1s, a series of potential inhibitors were synthesized and tested for their inhibitory activity. Synthesizing two series of chemical probes: $\alpha$-naphthoflavone-like and $\beta$-naphthoflavone-like pyranoflavones, Liu et al. created ligand models of CYP1A1 and CYP1A2. The molecular surface images were generated in UCSF Chimera 1.6.2. (UCSF San Francisco, CA) after energy minimization using the conjugate gradient method with the CHARMM force field. The authors concluded that CYP1A 1 has a narrow and long cavity, $15.8 \AA$ in length and $4.6 \AA$ in width. The CYP1A2 cavity can accommodate a triangular molecule, showing a planar heart-like structure with a 9.1 A long side and a $7.0 \AA$ short side [53]. According to that suggestion, a series of 14 flavone and coumarin derivatives exhibiting a triangular planar shape were designed with the use of the computer-assisted alignment assay. Most of the tested compounds (13 out of 14) appeared to be selective CYP1A2 inhibitors. 4-Trifluoromethyl-7,8-pyranocoumarin and 7,8-furanoflavone were found to be the most effective CYP1A2 inhibitors with $K_{i}$ at a submicromolar level [88].

In conclusion, the detailed topology of the CYP1A1 active site is more similar to the CYP1B1 cavity than to the cavity of CYP1A2 [25]. The closer similarity between the CYP1A1 active site and CYP1B1 compared with the CYP1A2 active site may influence the substrate profiles of these enzymes, which are more similar for CYP1A1 and CYP1B1 than for CYP1A1 and CYP1A2.

\section{Mutations}

The molecular modeling of enzymes differing in a selected amino acid sequence provides a rationale for substrate specificity. Studies of the relationship between an amino acid sequence and the functionality of CYP1s were possible, thanks to mutagenesis methods. To reduce the number of mutants to be constructed, the residues for replacement should be located in the active site of the enzyme and must be different from the corresponding residues in the enzyme which is being compared. Based on the knowledge of which active site residues are different between CYP1A1 and CYP1A2, the effect of reciprocal mutations on substrate specificity was examined [31]. The residue replacement in the substrate recognition site (SRS) reduced 7-methoxyresorufin (7-MR) and 7-ethoxyresorufin (7-ER) O-dealkylase activities, except for the CYP1A1 S122T mutation which increased both activities. The results confirmed the importance of SRSs for enzymesubstrate interaction, proposed earlier by Gotoh [89].

Functional alterations as a result of genetic polymorphism may influence the therapeutic response of many drugs changing their efficacy and toxicity. CYP1A2 participates in the metabolism of $9 \%$ of all medicines [6]. The CYP Allele Nomenclature Committee (http://www.cypalleles.ki.se/cypla2. htm) has recognized 40 CYP1A2 variant alleles. A functional characterization of 20 allelic variants of CYP1A2 was performed with two substrates: phenacetin and 7- ethoxyresorufin [90]. Four of the studied alleles, which exhibited the substitutions critical to the enzymatic function (located in: SRS, the heme-binding region, the aromatic region, and the proline-rich region), showed reduced activity toward both substrates. However, the substitution Arg377Gln might cause a change in hydrogen bonds to alternative ones with other amino acids, which resulted in the loss of enzyme activity or decreased holoprotein level. Two variants with the substitutions Thr438Ile and Asp436Asn showed a significantly higher activity toward phenacetin than the wild-type enzyme. Interestingly, the amino acid residues Thr438 and Asp436 are not located in the substrate binding site. They are situated on the surface of CYP1A2 and may influence the interaction of the enzyme with cytochrome b5 [90].

Zhang et al. [78] applied molecular dynamics simulations and structural analyses to elucidate mechanisms of mutation-induced allostery in CYP1A2. They explored the effects of a peripheral mutation, F186L, at $\sim 26 \AA$ away from the enzyme active site on the enzyme catalytic activity. For these mutations, they found a change in protein flexibility and a collective protein motion that caused the main substrate access channel to be mostly closed. Dynamics simulations were used to explain the mechanism of a changed binding of 7-ethoxyresorufin in the catalytic pocket of the F186L mutant enzyme. Ma et al. demonstrated an impact of F186L mutation on the function of CYP1A2 [91]. Despite the fact that the mutation Phe186Leu is located on the surface, a series of changes in the catalytic pocket were observed. Phe186Leu mutation enhanced the binding affinity but lowered the O-deethylation velocity of 7-ethoxyresorufin. It was suggested that channel $2 c$, which is the main active channel in CYPs [92], is closed in the mutant CYP1A2 enzyme as a result of B'helix/B-C loop stabilization.

Allelic CYP1B1 variants were constructed in studies of the substrate metabolism catalyzed by CYP1B1 [82, 93, 94]. Mutant forms of CYP1B1 have been discovered in the childhood disease primary congenital glaucoma (PCG). Homology-modeled structures of wild-type and diseaseassociated mutant forms were constructed on the basis of human CYP2C9. In the mutant form of CYP1B1, changes in the geometry of the substrate binding region and the position of the heme were observed. Using molecular dynamics simulations, altered interactions of estradiol with the disease mutant of CYP1B1 in comparison with the wild type of enzyme were demonstrated [83].

More recently, the structures of eight mutants differing only in one residue were generated from the crystal structure of CYP1A2. Mutation of only one amino acid changed the enzyme static structure even in distant regions of the protein and influenced the flexibility of the whole protein and influenced the catalytic activity of the enzyme by changing the conformation of a ligand-enzyme complex [81]. Significant changes in the dynamic properties of CYP1A2 were observed when long-time MD simulations (100 ns or longer) were used.

\section{The Molecular Docking of Ligands}

Molecular docking is a computational approach which predicts the orientation of a ligand (pose) in complex with 
a protein target and assesses its binding affinity using scoring functions.

Structure-based drug design is performed in order to identify bioactive compounds in the compound pool found in high-throughput virtual screening (HTVS) based on the information from the protein structure. In structure-activity relationship studies, molecular docking helps to elucidate the bioactivity of lead compounds identified at the "hit-to-lead" stage on the basis of a ligand-target interaction analysis.

A computational approach predicts the orientation of ligands in complex with a protein target using scoring functions (specific algorithms). Structure-based virtual screening is a quick and more economical method of lead identification than experimental screening. In research, popular open-source docking software and more advanced commercial packages are used. Nonetheless, in the opinion of many authors, they still need to be improved to obtain a better pose prediction capability. The main factors limiting the accuracy of docking results are protein flexibility and solvation. The affinity of a ligand to a protein target is characterized by scoring functions which represent a relative binding free energy based on protein-ligand interactions. Scoring functions do not consider the contribution of thermodynamic effects on binding free energy like solvation, long-range interactions, and conformational changes. Protein-ligand docking methods are widely used at different stages of the drug design process. They are employed at the beginning for the virtual screening (VS) of large ligands' databases and at the lead optimization stage.

The scoring function is used by the searching algorithm to identify the best pose of a particular ligand, the most energetically favoured orientation inside the active site. It also estimates the binding affinity of a ligand. This allows us to rank ligands in virtual screening, where large and chemically diverse databases should be docked very effectively; so here, the speed of docking is more important than its accuracy [5]. However, in lead optimization, researchers are interested in obtaining docking results that are as accurate as possible for a small set of ligands, which are often structurally related. Besides assessing binding affinities to the macromolecular target for close analogues in lead optimization, docking can also be used for predicting off-target binding to related proteins and to cytochromes as drugmetabolizing enzymes [5].

The role of a docking algorithm is to generate ligand poses inside the binding site. The scoring function should correctly recognize the bioactive orientation and assign a sufficiently high score to it, allowing us to discriminate binders from nonbinders in terms of calculated binding affinity [5]. Scoring functions are classified as force fieldbased, empirical, and knowledge-based [95]. Force fieldbased functions account for electrostatic and van der Waals interactions in protein-ligand complexes using force field parameters. In empirical scoring, functions are terms describing specific ligand-protein interactions, for example, hydrogen bonds, ionic interactions, or hydrophobic effects. Another class of scoring functions, knowledge-based, was derived from a statistical analysis of the crystal structures of ligand-protein complexes. It does not use information about experimental activity but analyzes the distribution of ligandprotein atom pairs giving pairwise potentials [95].

All scoring functions have some limitations. They perform much better in identifying correct poses of individual ligands than in ranking ligands according to their activity for respective targets. Difficulty in differentiating between nanoand micromolar compounds limits the reliability of docking [5]. To overcome this issue, more than one scoring function can be employed in assessing binding affinity. Consensus scoring combines the results of several scoring functions; this approach is in some cases more successful in predicting activity than a single function [95].

Some specific interactions, for example, cation-pi, $\mathrm{CH}$ pi, or weak hydrogen bonds, are not captured by commonly used scoring functions. Also, many simplifications, such as treating solvation effects and contributions of entropy to the binding energy, result in a poor ranking of compounds in VS [95]. Therefore, more advanced and computationally demanding methods for rescoring docked poses are applied. For this purpose, physics-based methods and simulations based on force fields and implicit solvent models are employed. Among them, commonly used approaches are the molecular mechanics-Poisson-Boltzmann surface area (MM-PBSA) and the computationally less demanding molecular mechanics-generalized Born surface area (MMGBSA).

Many docking algorithms treat the receptor as conformationally rigid, which is a severe approximation influencing the final results. In fact, upon binding to a protein, ligands often induce changes in its conformation $[5,96]$. The flexibility of a protein can be included in the macromolecular model in several ways. The simplest one is using "soft" receptors (soft docking) with decreased energy penalties for steric clashes between the ligand atom and the receptor. Other docking methods accounting for protein flexibility are a docking using side-chain flexibility, in which side-chain rotations of residues in the binding site are allowed, a docking using an ensemble of receptor structures (experimental or simulated), and on-the-fly docking, where protein conformations are generated "on the fly" during docking by exploring the protein's degrees of freedom [5, 97].

There are many examples of ligand-target interactions via water molecules (e.g., hydrogen bonding), so neglecting water molecules could be an additional source of errors in docking. Usually, before docking, water molecules are removed from the binding site, but there are also other options, such as keeping or displacing water molecules which are placed in the binding site or are important for the binding of ligands $[5,95]$.

Existing scoring functions are not perfect in ranking compounds in virtual screening and estimating absolute binding affinities in lead optimization. Also, receptor flexibility needs to be taken into account during docking experiments. Therefore, docking methods are still under development regarding aspects such as receptor flexibility, structural water or the solvation, and entropic effect [98].

Docking can predict a plausible orientation and conformation of ligands inside the binding site of the receptor, although this method gives only a static picture of ligandreceptor interactions. A deeper insight into the time- 
dependent properties of ligand-protein complexes could be obtained with the use of molecular dynamics (MD) simulations. In molecular dynamics simulations, solvent molecules are included explicitly or with the use of implicit solvent models. MD, an invaluable tool in SBDD, has many applications. Before docking, MD simulations could be used to give an ensemble of protein structures, but for postdocking complexes, this method allows for a computational testing of its stability and is often used to rescore docked ligands because of the improvement in the mutual fit and optimization of interactions that occur during the simulation. Calculations of binding free energy $\left(\Delta G_{\text {bind }}\right)$ could be made using different methods, such as thermodynamic integration (TI), free energy perturbation (FEP), linear interaction energy (LIE), and the aforementioned MM-PBSA or MM-GBSA approaches [99]. There are many examples of successful applications of MD in the characterization of ligand-macromolecular target complexes $[4,99]$.

Protein-ligand binding energy should be determined as a nonadditive effect, which depends on the chemical environment and protein-ligand cooperative dynamic processes. Molecular dynamics simulation improves predictions of binding free energy by considering the time-dependent behaviour of the macromolecular system in response to changes in its molecular environment. However, docking results are not always consistent with MD simulation (different poses observed by docking and MD; a ligand does not form a long-lasting complex). It also happens that docking results are not proved by the biochemical assay in vitro, and vice versa; compounds with high bioactivities are shown to have a poor docking score. Many scientists point to the limitations of docking procedures [2, 69]. Table 1 presents a survey of studies devoted to computer-aided analysis of interactions of CYP1 enzymes with their ligands.

\section{Substrates and Inhibitors of CYP1s}

A classification of inhibitors and noninhibitors of CYPs is particularly important in relation to drug design and the prediction of drug-drug interactions. CYP1A2 is responsible for the biotransformation of $\sim 5 \%$ of currently used drugs. Screening a set of compounds from a database in search of CYP1A2 ligands seems to be more efficient than an experimental determination of catalytic activities of a series of compounds. However, the use of scoring functions did not always give satisfactory results. Better results were achieved with recently developed nonlinear machine learning methods. Seven thousand test compounds from a database were analyzed as CYP1A2 inhibitors. The accuracy of the developed method for the prediction of inhibitory activity was estimated at $73-76 \%$ [86], while the decision tree model based on Lipinski's rule of five classified $67 \%$ of the test compounds correctly. Binding free energies of structurally diverse CYP1A2 substrates and inhibitors were predicted with the use of the linear interaction energy (LIE) method. For $10 \mathrm{com}$ pounds (from the set of 13 test ligands), the difference between the calculated and experimental binding free energies was smaller than $4.0 \mathrm{~kJ} / \mathrm{mol}$ [70]. CYP1A2 ligands were identified from a large compound library (16,338 compounds) with the use of two approaches: structure-based and ligandbased virtual screening. As compared to the ligand-based method, the structure-based method identified more inhibitors which were more potent as well [100].

In this review, we present studies on specific interactions of substrates/inhibitors with CYP1 isozymes, which allowed for an analysis of the relationship between the structure of the tested compounds and their inhibitory activities. The studies on ligand-CYP1 enzyme interactions with the use of computational methods are summarized in Table 1 . There are some groups of compounds that are particularly interesting, and many reports devoted to their interactions with CYP1s are discussed below. These are endogenic substrates, alkoxyresorufins, polycyclic aromatic hydrocarbons, and compounds that are supposed to play a role in cancer chemoprevention: natural flavonoids and trans-stilbene derivatives. The bioactivity of natural chemopreventive agents inspired researchers to synthesize their derivatives in order to study the structure-activity relationship and to obtain more active and efficient chemopreventive agents.

5.1. Endogenic Substrates. 17- $\beta$-Estradiol (E2) is metabolized by CYP1s to 2-hydroxy, 4-hydroxy, or 16-hydroxy derivatives. The order of preference for in vitro 2-hydroxylation by CYP1 isoforms was CYP1A2 > CYP1A1 > CYP1B1; for 4hydroxylation, it was CYP1B1 > CYP1A2 > CYP1A1; and for 16-hydroxylation, CYP1A2 showed the highest preference followed by CYP1A1 and CYP1B1. In the mammary gland, CYP1A1 catalyzes predominantly 2-hydroxylation. 2Hydroxyestradiol $\left(2-\mathrm{OHE}_{2}\right)$ is further methylated by catechol-O-methyltransferase to produce 2-methoxyestradiol, which does not exhibit carcinogenic activity. On the contrary, it inhibits the proliferation of cancer cells. 4-Hydroxyestradiol $\left(4-\mathrm{OHE}_{2}\right)$ is produced in a reaction catalyzed mainly by CYP1B1 [101, 102]. The product of $4-\mathrm{OHE}_{2}$ oxidation (estradiol-3,4-quinone) forms quinone-DNA adducts and initiates carcinogenesis [103]. With the use of homology models of CYP1A1 and CYP1B1 based on the crystal structure of CYP1A2, Itoh et al. analyzed the structural causes of different sites of E2 metabolism [44]. The studies revealed one binding mode of E2 (18-methyl group up) to CYP1A1 and CYP1A2 and two binding modes of E2 (18-methyl group up and down) to CYP1B1. Thr124 and Phe260 of CYP1A2 and Ser 122 and Phe 258 of CYP1A1 were identified as causing steric hindrance with the B-ring of E2. Ala133 and Asn265 of CYP1B1 are critical residues influencing the interaction of E2 with the binding site. Conformations of E2 in enzyme cavities decided on the site of E2 metabolism leading to the hydroxylation preferentially at the position 2 in case of CYP1A1 and CYP1A2, and at the position 4 in CYP1B1 [44].

Fatty acids are an essential class of CYP endogenic substrates whose metabolites are supposed to play a physiological role in the cardiovascular system. With the use of molecular docking, regiospecificity of the metabolism of arachidonic acid (AA) and eicosapentaenoic acid (EPA) catalyzed by human recombinant CYP1A1 in the reconstituted 
enzymatic system was studied. Interestingly, AA was mainly metabolized to 19-hydroxyarachidonic acid by CYP1A1. With EPA as a substrate, CYP1A1-dependent epoxygenase activity leading to the regiospecific and stereoselective formation of $17(R), 18(S)$-epoxyeicosatetraenoic acid $(68 \%)$ and 19-hydroxy-EPA (31\%) was demonstrated [30]. The molecular docking of AA and EPA to the CYP1A1 active site revealed that fatty acids interact with the same amino acid residues as alkoxyresorufins and benzo(a)pyrene, although additional residues located in the access channel may interact with AA and EPA owing to their longer molecules. Conformations of fatty acids in the CYP1A1 binding site are stabilized at their carboxy ends by hydrogen bonds, while resorufin and benzo(a)pyrene are mainly stabilized by hydrophobic interactions [30]. The complexes of AA and EPA with CYP1A1 were further examined with MD simulations to obtain productive binding modes. The in silico site scoring of geometric criteria, angles and distances of the substrates to the ferryl oxygen, confirmed that steric factors play a key role in the regiospecificity of CYP1A1-mediated metabolism [33].

5.2. Alkoxyresorufins. Alkoxyresorufins are CYP1 substrates used in activity assays. Lewis and Lake [22] initiated the computational approach in the studies of substrate affinity to CYP1 binding sites. In the 1990s, homology models of CYP1A1 and CYP1A2 binding sites were generated from the bacterial CYP102 crystal structure via residue replacement and energy minimization procedures, and a series of known substrates and inhibitors of the CYP1A subfamily were docked interactively to the active sites [22]. The orientation of 7-MR and 7-ER in binding site cavities was determined with the aim of elucidating their substrate specificity; 7-MR is a specific substrate of CYP1A2, while 7-ER demonstrates a higher affinity to CYP1A1 over CYP1A2. The enzymes share $72 \%$ of the amino acid sequence identity; however, the differences in their structures seem to be sufficient to explain their specific affinity to the ligands. Critical changes in the CYP1A1 and CYP1A2 structures were found. In the I helix, the change from aspartate adjacent to Thr268 in CYP1A1 to glutamate in CYP1A2 gives rise to the steric restriction in the CYP1A2; as a result, there is no sufficient space for 7-ER in the binding site of CYP1A2. Moreover, in the F helix, which lies above the heme moiety, there are amino acid residues that are donors of hydrogen for the carbonyl group being located in resorufins on the opposite side of a molecule; in CYP1A1, the carbonyl group of 7-ER can form a hydrogen bond with Thr185, while 7-MR can form a hydrogen bond with Asp184 in CYP1A2 [22].

Szklarz and Paulsen [28] docked 7-MR and 7-ER manually to the CYP1A1 binding site (homology model generated from CYP2C5) in the orientations, leading to the formation of major products. The residues located within $5 \AA$ were identified. Val382 was found as a key residue that stabilized 7-ER in the CYP1A1 binding site through van der Waals interactions [28]. This interaction did not occur in the case of 7-MR. Moreover, a higher activity of CYP1A1 toward 7-ER may be explained by interaction energy, which is significantly higher for 7-MR (lower absolute value). The effects of five key residues-Ser122, Asn221, Gly225, Leu312, and Val382 in CYP1A1, and Thr124, Thr223, Val227, Asn312, and Leu382 in CYP1A2-on the substrate specificity of enzymes were investigated [31]. Specificity changes were observed, but no single mutation that could confer the activity of one isoform onto another was found. As a continuation of studies, 26 possible multiple mutants of CYP1A2 were constructed and investigated with the molecular dynamics-based scoring method. In 7 mutants, the specificity shift from CYP1A2 to CYP1A1 was predicted. For 5 mutants, the prediction was confirmed by site-directed mutagenesis and biochemical assays [68].

When 7-ER was docked to CYP1A1 generated using CYP1A2 as a template, the amino acid residues found within a $3 \AA$ radius from the substrate were Ser120, Ser12, Phe123, Phe224, Phe258, Tyr259, Asp313, Thr321, Val382, and Ile386. For this CYP1A1 structure, substrate inhibition kinetics was observed, probably due to a nonproductive orientation of 7 ER in the CYP1A1 binding site. Docking studies showed that the symmetrical molecule of 7-ER may be bound in a reverse orientation with the ethoxy group directed in the opposite side of the heme, which is energetically favourable in the CYP1A1 wild type and mutants [34].

5.3. Polycyclic Aromatic Hydrocarbons. Polycyclic aromatic hydrocarbons, present ubiquitously in the environment, are planar aromatic compounds produced mainly in combustion processes. Benzo $(a)$ pyrene is a procarcinogen activated by CYPs to mutagenic products which form adducts with DNA. Its metabolism by CYP1s has been studied with the use of molecular docking since the 1990s [22]. The studies have been continued by Szklarz and collaborators [28, 33], who found a correlation between the numbers of docked orientations within $4 \AA$ of the ferryl oxygen and experimentally determined metabolite ratios. The regiospecificity of $\mathrm{B}(a) \mathrm{P}$ metabolism was demonstrated with a homology model based on the CYP 2C5 crystal structure of CYP1A1 [33] and with the use of multiple models of killifish, scup, rat, and human CYP1A1s [37]. In all the models analyzed, the 8,9-bond was more frequently close to ferryl oxygen than 7,8 - or 9,10-positions. However, 8,9-epoxide production has never been observed owing to unfavourable formation energy. The formation of epoxides in the close vicinity of 8,9-position-7,8-epoxide or 9,10-epoxide-is supposed to be a result of a small reposition of a substrate molecule by vibration or rotation within the active site [37].

CYP1B1 inhibition by eleven polycyclic aromatic hydrocarbons (PAHs) and 14 acetylenic PAHs and biphenyls was studied. Five of the potent inhibitors with $\mathrm{IC}_{50}$ at the nanomolar level (benzo(a)pyrene, dibenzo[aj]acridine, 1-(1propynyl)pyrene, 3-(1-propynyl)phenanthrene, and benzo [j]fluoranthene) were docked to the CYP1B1 and CYP1A2 cavities showing different binding modes for selected aromatic hydrocarbons [104].

An alternatively spliced variant of CYP1A1 having a deletion of exon 6 was discovered in human brain tissue [35]. The lack of $\mathrm{B}(a) \mathrm{P}$ metabolism to genotoxic ultimate carcinogens by the exon 6 del CYP1A1 was elucidated by molecular docking studies. $\mathrm{B}(a) \mathrm{P}$ docked to the wild CYP1A1 (being modeled with the CYP2C5 crystal structure) was situated in a way that made possible an oxidation 
reaction in the positions $7,8,9$, and 10 of the aromatic ring. Two major clusters of orientations were found, out of the 6 observed for the $\mathrm{B}(a) \mathrm{P}$ molecule docked to the CYP1A1 binding site: the first with $7,8,9$, and 10 positions near the heme iron (72\% of all 50 studied conformations) and the second with position 3 close to the heme (14\% of conformations). Among 11 orientations found for $\mathrm{B}(a) \mathrm{P}$ in the exon 6 del CYP1A 1 active site, in two main orientations, C-3 was in a close proximity to the heme [99]. However, the 3hydroxylated product of $\mathrm{B}(a) \mathrm{P}$ metabolism is not considered as genotoxic. $\mathrm{B}(a) \mathrm{P}$ was differentially orientated in the CYP1A2 and CYP1B1 binding sites; positions 7, 8, 9, and 10 of the aromatic scaffold were observed in proximity to the heme iron only in the CYP1A2 binding cavity [104].

A collection of 22 polycyclic aromatic hydrocarbons of increasing size were docked to wild-type and chimeric CYP1A enzymes. The QSAR analysis revealed that the size of the substrate influences its accessibility to the enzyme cavity via access channels. A visualization of CYP1A enzymes with the use of CAVER software showed two regions located close to or within the CYP access channels affecting differentially small and large polycyclic substrates [58].

Polychlorinated dibenzo- $p$-dioxins (PCDDs) and coplanar polychlorinated biphenyls (PCBs) are a class of aromatic hydrocarbons demonstrating high genotoxicity. The metabolism of dioxins and PCBs shows the species-based differences between humans and rats [55]. Human CYP1s metabolized efficiently low-chlorinated PCDDs, while 2,3,7,8tetrachlorodibenzo- $p$-dioxin (TCDD) metabolites were not detected. Rat, but not human, CYP1A1 metabolized $3,3^{\prime}, 4,4^{\prime}, 5$-pentachlorobiphenyl, the most toxic PCB, to two hydroxylated derivatives showing lower toxicity than the parent compound. Docking studies with the use of homology models of human and rat CYP1A1 indicated essential amino acids residues (Ala120 and Phe316) for 3,3',4,4',5-pentachlorobiphenyl metabolism. The differences in amino acid residues led to changes in the size and shape of the cavities; in the rat CYP1A1 cavity, 3,3',4,4',5-pentachlorobiphenyl was close enough to the heme to be metabolized [45].

Species-based differences were studied by the docking of $\mathrm{B}(a) \mathrm{P}, 3,3^{\prime}, 4,4^{\prime}$-tetrachlorobiphenyl (TCB), and TCDD to multiple models of rat, human, killifish, and scup CYP1A1 [37]. Mutating interacting residues of killifish CYP1A1 to corresponding residues of human CYP1A1 led to TCB poses similar to those of human CYP1A1. A slower oxidation of TCDD in comparison to TCB by each species may be explained by structural constraints in the enzyme binding site. A slower metabolism of TCDD by human CYP1A1 than rat CYP1A1 resulted from the lower frequency of productive poses in human CYP1A1.

The molecular docking of 37 polycyclic aromatic hydrocarbons, corresponding diols, and heterocyclic hydrocarbons to homology models of CYP1A1 and CYP1B1 based on the crystal structure of CYP1A2 was performed with LigandFit and CDOCKER algorithms [50]. The analysis of CYP1A1 and CYP1B1 binding sites revealed their hydrophobic character due to hydrophobic residues, mainly the phenylalanines Phe123, 224, and 258 in CYP1A1 and Phe134, 231, and 268 in CYP1B1, which may interact through $\pi-\pi$ stacking with aromatic ligands. However, potential hydrogen bond donor residues, Ser122, Asn221, Leu312, Asp313, Gly316, Ala317, and Asp320, found in the CYP1A1 binding site and corresponding residues in CYP1B1, Ala133, Asn228, Thr325, Asp326, Gly329, Ala330, and Asp333, stabilized the ligand molecules by hydrogen bonds. The amino acid residues which mainly interact with the ligands under study are located in the substrate recognition sites classified by Gotoh [89]. Interestingly, the CDOCKER docking procedure gave the best results for CYP1A1 linear statistical analysis, while LigandFit appeared to be a more suitable procedure for CYP1B1 [50].

5.4. Flavonoids. Flavonoids are a large class of natural bioactive compounds present in fruits and vegetables. Their role in cancer prevention is established in epidemiologic studies [21]. In experimental in vitro studies, flavonoids appeared to be potent inhibitors of CYP1s. A correlation was found between the inhibition of CYP1A1 and CYP1A2 activities by flavonoids differing in the position and number of hydroxyl groups and theoretical descriptors obtained from quantum mechanical calculations and molecular dynamics of the ligand-enzyme complex [32]. In this report, quercetin and kaempferol docked to the binding site of CYP1A2 were demonstrated, and amino acid residues responsible for ligand-enzyme interactions that may be useful in site-directed mutagenesis were found. Takemura et al. demonstrated a selective inhibition of CYP1B1 by flavonoids, particularly chrysoeriol and isorhamnetin. To explain their strong effect on CYP1B1, a molecular docking approach was employed [42]. For this purpose, they constructed three-dimensional structures of CYP1A1 and CYP1B1 by homology modeling, using the crystal structure of CYP1A2. The authors concluded that methoxyflavonoids - chrysoeriol and isorhamnetin-fit well into the active site of CYP1B1, while in active sites of CYP1A1 and CYP1A2, there occurred a steric collision between methoxy substituents and Ser-122 in CYP1A1 and Thr-124 in CYP1A2. The binding specificity of methoxyflavonoids is based on interactions between methoxy groups and specific CYP1 residues. Methoxyflavonoids possessing a 2-3 double bond in the C-ring, as selective inhibitors of CYP1B1, are supposed to be chemopreventive agents against CYP1B1related carcinogenesis.

Oroxylin and wogonin are biologically active compounds occurring in the extract of roots of Scutellaria baicalensis, used in traditional oriental medicines [76]. Oroxylin and wogonin are inhibitors of CYP1A2 with $\mathrm{IC}_{50}$ values of 579 and $248 \mathrm{nM}$. With the use of molecular docking, molecular dynamics simulation, and MM-PBSA, the mechanism of the inhibitory action of flavonoids differing in the position of a hydroxyl group was analyzed. Calculated binding free energies of ANF $(-23.5 \mathrm{kcal} / \mathrm{mol})$, wogonin $(-21.1 \mathrm{kcal} / \mathrm{mol})$, and oroxylin $(-19.8 \mathrm{kcal} / \mathrm{mol})$ are significantly overestimated; however, they are in accordance with the order of experimentally determined inhibitory activities. The difference in the affinity of oroxylin and wogonin to the CYP1A2 active site was explained by 
molecular dynamics and molecular docking; for ANF and wogonin, noncovalent interactions (van der Waals and hydrophobic interactions) influenced the stability of their complexes with CYP1A2. In the CYP1A2-oroxylin complex, there occurred an energetically unfavourable repulsion between Thr118 and the methoxy group at position 6 in the oroxylin molecule. As a result, conformational changes in the side chain of Thr118 were observed, which caused the formation of a more open and larger binding site cavity of CYP1A2 and a weaker inhibitory activity of oroxylin. Moreover, the $\mathrm{O} 7$ atom of oroxylin formed a strong hydrogen bond with Asp313, as the $\mathrm{O} 5$ and $\mathrm{O} 6$ atoms formed two hydrogen-bonding interactions with a molecule of water. These interactions were not observed in complexes of CYPA2 with wogonin and ANF [76].

Chrysin (5,7-dihydroxyflavone), a natural, biologically active flavonoid extracted from plants and honey, exhibited an inhibitory activity toward CYP1A2 comparable to ANF $\left(\mathrm{IC}_{50}\right.$ values of $54 \mathrm{~nm}$ versus $\left.49 \mathrm{nM}\right)$. With molecular docking and molecular dynamics simulations, the interactions in the enzyme binding site were estimated. The complex of chrysin with CYP1A2 was stabilized with van der Waals interactions, H-bond with Asp313, and stacking interactions with Phe226 [71]. The affinity of chrysin to CYP2C9 was significantly weaker because van der Waals interactions in the larger pocket of CYP2C9 were not as strong as in CYP1A2.

Based on the known inhibitory activity of compounds, more efficient inhibitors can be designed. Flavone derivatives with an acetylene group linked to the flavone backbone showed a comparable ANF inhibitory activity against CYP1A1. Moreover, mechanism-based inactivators of CYP1A1 were found. 4'-Ethynylflavone and 7-ethynylflavone irreversibly inactivated half of the CYP1A1 activity in less than two minutes. The acetylene group is probably responsible for irreversible enzyme inactivation. Docking simulations revealed the orientations of ethynylflavones in the CYP1A1 binding site with the acetylene group toward the heme. Only $2^{\prime}$-ethynylflavone demonstrated another orientation in the CYP1A1 cavity; this compound appeared to be a selective inhibitor of CYP1A2. In all the studied ethynylflavones docked to CYP1A2, acetylene groups were oriented away from the heme [54].

5.5. Stilbenoids. Since the 1990s, natural stilbenoids-transresveratrol (3,4',5-trihydroxy-trans-stilbene; RESV), pterostilbene (3,5-dimethoxy-4'-hydroxy-trans-stilbene), and piceatannol (3,4,4',5-tetrahydroxy-trans-stilbene)-have been extensively studied in relation to chemoprevention [105]. RESV is a natural polyphenol found in grapes, berries, and peanuts, showing well-characterized beneficial bioactivities $[106,107]$. It efficiently and selectively inhibits CYP1 activities $[108,109]$, although its bioavailability in humans was determined as poor [110] due mainly to conjugation reactions with sulphuric acid and glucuronic acid. In the last two decades, natural and synthetic RESV analogues have been studied in the context of their interaction with CYP1s. It has appeared that natural trans-resveratrol analogues-pinostilbene, rhapontigenin, desoxyrhapontigenin, and pterostilbene, which possess some of the hydroxyl groups substituted by methoxy groups-are more potent CYP1A1 and CYP1A2 inhibitors than trans-resveratrol $[111,112]$. Therefore, the substitution of hydroxyl groups with methoxy substituents efficiently influenced the affinity of compounds to active sites of cytochromes and, moreover, improved bioavailability by preventing polyphenol metabolism. Consequently, the interest focused on synthetic derivatives of trans-stilbene appeared to be more promising with regard to their interaction with CYP1 enzymes.

The pattern of substituents linked to the trans-stilbene core exerts a decisive effect on the affinity of stilbenoids to active sites of cytochromes P450 family 1. The positions of some substituents influence the ligand orientation and interactions with amino acid residues in the enzyme active site, affecting the distance to the heme, which determines the course of enzymatic reaction. In the studies of Chun et al. [75, 112-114], $3,5,2^{\prime}, 4^{\prime}$-tetramethoxy-trans-stilbene and 2,4,2',6'-tetramethoxy-trans-stilbene were identified as very potent CYP1B1 inhibitors, indicating a distinctive role of methoxy substituents in positions 2 and 4, as well as 2 and 6 in the inhibition of CYP1B1 activity.

The design of the series of polymethoxy-trans-stilbenes with the constant motif of 3,4-dimethoxyphenyl influenced the way the ligands were oriented in the enzyme binding site [56]. The molecular docking of trans-stilbenes to the CYP1A2 active site showed the most favourable orientation with the ring possessing the altering pattern of substituents directed to the heme (orientation A; Figure 5(a)). However, in CYP1B1, 2',3,4-trimethoxystilbene was oriented with 3,4-dimethoxyphenyl directed toward the heme (orientation B; Figure 5(b)). This orientation occurred in 17 out of a total of 20 poses and was energetically favourable in comparison to orientation A; the interaction energy and binding energy for the ligand calculated for orientation B was higher by $12 \mathrm{kcal} / \mathrm{mol}$ and $40 \mathrm{kcal} / \mathrm{mol}$, respectively [56]. A very strong affinity of $2^{\prime}, 3,4-$ trimethoxystilbene to the CYP1B1 binding site was expressed by the highest value of binding energy $(\Delta G)$ in comparison to other compounds of the series. The analysis of the interaction between ligands and amino acid residues in the CYP1B1 active site demonstrated the occurrence of $\pi-\pi$ stacking interactions for both phenyl rings of $2^{\prime}, 3,4$-trimethoxystilbene with Phe231 (Figure 5), whereas a hydrogen bond was observed only for the opposite ligand orientation (Figure 5(a)), which was less energetically favourable [56]. In this bonding, Gln332 was engaged; the same amino acid residue formed a hydrogen bond with $4^{\prime}$-methylthiostilbenes. Therefore, it may be supposed that the effect of hydrogen bonds on the ligand affinity to the cytochrome P450 active site is not of primary importance. Hydrophobic interactions between methoxy groups and amino acid residues seem to be more essential in determining the inhibitor affinity to cytochrome P450. Moreover, 2',3,4-trimethoxy-trans-stilbene is characterized by a high selectivity of action; it inhibits CYP1B1 90 times more strongly than CYP1A1 and 830 times more strongly than CYP1A2. Thus, the $2^{\prime}, 3,4$-triMS molecule appeared to be a comparably effective CYP1B1 inhibitor than the molecules designed earlier [106-108], demonstrating an 


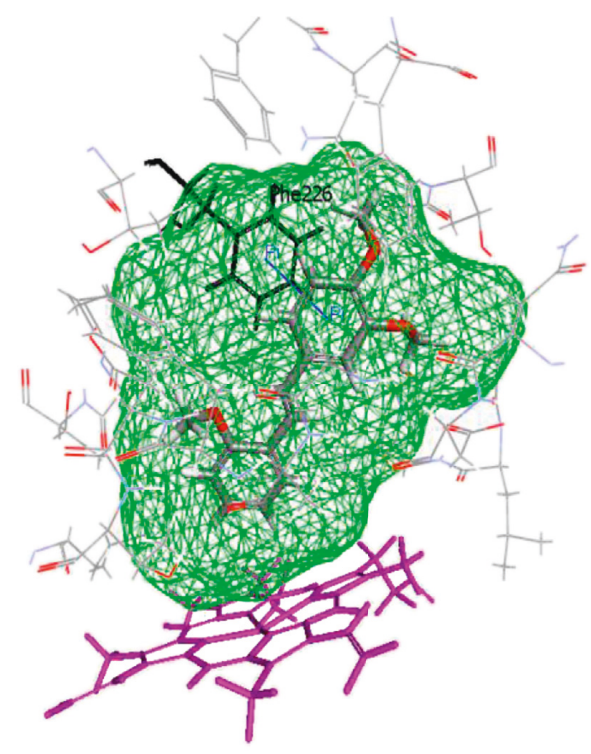

(a)

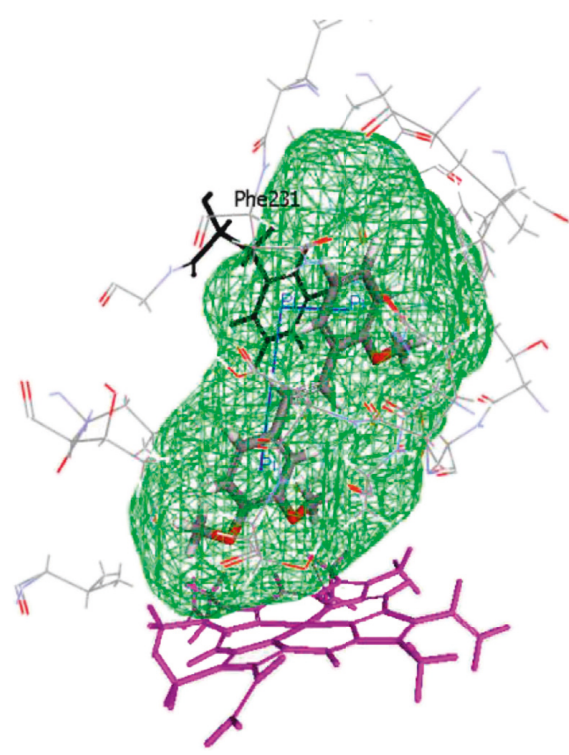

(b)

FIgure 5: 2' 3,4-trimethoxy-trans-stilbene docked to the CYP1A2 (a) and CYP1B1 (b) binding sites. Amino acid residues surrounding the active sites are visualized with Phe226 and Phe231 in black colour. The heme is represented as a stick model in pink. The solid blue lines represent $\pi-\pi$ stacking interactions.

effective inhibitory action of the compound with a pattern of methoxy groups in positions $2^{\prime}, 3$, and 4 [56].

In search of novel CYP1 inhibitors, methylthiostilbene derivatives were designed and synthesized [63, 77]. The orientation of a series of polymethoxy-trans-stilbene derivatives containing a $4^{\prime}$-methylthio substituent in the CYP1 active sites was studied, and molecular interactions between ligands and amino acid residues of the enzyme pocket were estimated. The orientation with a $4^{\prime}$-methylthiophenyl ring toward the heme for the studied derivatives in CYP1A2 and CYP1B1 active sites was the most favoured one. For this series of compounds, Phe226 and Phe260 in CYP1A 2 and Phe231 in CYP1B1 were involved in $\pi-\pi$ stacking interactions that stabilized the orientation of ligands in the enzyme active sites. Additionally, for some of the examined compounds docked to CYP1B1, an active site hydrogen bond was formed with Gln332. However, it should be mentioned that the occurrence of the hydrogen bond did not correlate with the inhibitory effect on enzyme activity. An important role is assigned to the hydrophobic interactions that may have an effect on the closer contact of docked molecules with the Fe atom of the prosthetic group, resulting in the hydroxylation of ligands. For 3,4,5-trimethoxy- $4^{\prime}$-MTS and 2,4,5-trimethoxy- $4^{\prime}$-MTS, the distances of $\mathrm{C}$ atoms in $3^{\prime}$ and $5^{\prime}$ positions to the Fe atom were shorter than 4.5 and $5.5 \AA$, respectively.

Stilbene derivatives better fit in the CYP1A1 binding site exhibiting a planar long strip cavity than in the CYP1A2 binding site with a more triangular shape [53], for example, the selective CYP1A1 and CYP1B1 inhibitor, 2,3,4-trimethoxy-4'-methylthio-trans-stilbene, did not fit the shape of the CYP1A2 binding pocket. The low affinity of 2,3,4,-trimethoxy- $4^{\prime}$-methylthio-trans-stilbene to the CYP1A2 binding site was additionally confirmed by a high strain energy $(103.09 \mathrm{kcal} / \mathrm{mol})$. By comparison, in the CYP1B1 binding site, the strain energy for 2,3,4-trimethoxy-4'methylthio-trans-stilbene was only $40.70 \mathrm{kcal} / \mathrm{mol}$ [77].

Another derivative, 2-methoxy-4'-methylthio-transstilbene, was found to be a selective and potent CYP1A1 inhibitor. Interestingly, its analogue, $2,4^{\prime}$-dimethoxy-transstilbene, was not so effective. For this derivative, docked to the CYP1A1 binding site, a high number of nonbonded molecular interactions were observed. However, the binding of 2-methoxy- $4^{\prime}$-methylthio-trans-stilbene was not favourable energetically [63].

\section{Other Ligands}

Most of the ligands of CYP1s are compounds with established pharmacological activity. They include drugs metabolized by the constitutive liver isozyme CYP1A2. A molecular docking of phenacetin and furafylline to CYP1A1 and CYP1A2 active sites was first performed by Lewis and Lake [22] with the use of homology models based on the CYP102 crystal structure. In 2012, Huang et al. studied the isoform-selective metabolism of phenacetin and acetaminophen with the use of the CYP1A2 crystal structure and homology model of CYP1A1 [49].

More recently, the metabolism of drugs selected from the Drug Bank comprising 1,528 drugs approved by the FDA was analyzed with the use of crystal structures of all isozymes of CYP family 1 . The substrates were divided into three groups: substrates having a single site of metabolism (SOM) but showing a different preference to get metabolized by CYP1A1, CYP1A2, and CYP1B (e.g., carvedilol, phenacetin, and bufuralol); substrates that are metabolized by any of the three isoforms (e.g., chloroquine and haloperidol); and substrates that show a different SOM and a different preference to isozymes (17- $\beta$-estradiol) [57]. Differences in substrate specificity among CYPs were studied for melatonin, 
debrisoquine, theophylline, clozapine, and lidocaine [60]. The regioselectivity of CYP1A2-mediated metabolism was investigated for caffeine, theophylline, acetanilide, naproxen, tacrine, amitriptyline, clozapine, and alkoxyresorufins by Jung and coworkers [67]. More recently, regioselective metabolism of acetaminophen catalyzed by CYP1A2 was proved through a molecular dynamics procedure [80].

Although many reports have demonstrated the inhibitory activity of alkaloids against the activities of CYPs [115], only for caffeine, theophylline [80], and rutaecarpine and its derivatives $[29,116]$, structural modeling has been performed. A good fitting of rutaecarpine with the binding site of the CYP1A2 model based on the rabbit CYP2C5 as a template was found [29]. Two hydrogen bonds can be formed between the keto and N14 groups of rutaecarpine and Thr208 and Thr473 residues of CYP1A2. The planar molecule of rutaecarpine forms $\pi-\pi$ stacking interaction between the C-ring and aromatic ring of the Phe205 residue. A possible orientation of coumarin in CYP1A1 and CYP1A2 binding sites for 3,4-epoxidation was demonstrated with enzyme structures based on the CYP2A5 crystallographic template. Key amino acid residues-Ser113, Phe205, Tre298, and Phe352-were identified for coumarin docked to CYP1A1 [116]. In the CYP1A2 binding site, Tre113, Phe205, and Tre298 participate in ligand-enzyme interaction. In both enzymes, Phe205 is responsible for $\pi-\pi$ stacking interaction with aromatic rings of the substrates. Both CYP1A1 and CYP1A2 metabolize coumarin in the same molecular positions.

In the context of cancer chemoprevention, naturally occurring isothiocyanates (ITCs) as inhibitors of CYP1s were studied. Sulforaphane, which is one of the most active chemopreventive agents and inhibitors of CYP1A1 activity, was docked to the CYP1A1 active site. Two hydrogen bonds between the nitrogen atom of sulforaphane and the hydrogen of the amino groups of Arg110 were found [51]. Moreover, sulforaphane suppressed the aryl hydrocarbon receptor (AHR) by binding to its ligand binding domain with hydrogen bonds. However, the studies did not explain the lack of potential to reduce the genotoxicity of TCDD.

Emodin is a natural anthraquinone extracted from Rheum emodi, a plant used in Chinese medicine. Among the CYPs studied (CYP1A1, CYP1A2, and CYP2B1), this anthraquinone demonstrated the most potent inhibitory activity toward CYP1A2 with the $\mathrm{IC}_{50}$ value of $3.73 \mu \mathrm{M}$ [117]. In the PubChem and ZINC chemical databases, 12 emodin analogues were found for further studies. Two of them (1-amino-4-chloro-2methylanthracene-9,10-dione (compound 1) and 1-amino-4hydroxyanthracene-9,10-dione (compound 2)) inhibited CYP1A2 with $\mathrm{IC}_{50}<1 \mu \mathrm{M}$, but only compound 1 was a mechanism-based inhibitor of both CYP1A1 and CYP1A2. Molecular docking revealed the orientation of molecules in the binding site, which make possible the abstraction of hydrogen from the 2-methyl group present only in compound 1. As a result, a benzylic carbon radical intermediate might be produced, which, after rearrangement, could form an irreversible complex with the enzyme. The radical can react with the iron-bound hydroxyl radical to form a hydroxylated metabolite, which acts as an inactivator of CYPs. A 2-methyl group of compound 1 docked to the CYP1A1 and CYP1A2 binding sites was found close to the heme moieties [117].

Combining in vitro studies with a computational approach enabled us to identify compounds that may interact with other drugs. This strategy appeared to be useful in the investigation of drug-drug interactions which are of great clinical importance in relation to multidrug disease treatment. Inhibitory effects of 91 kinase inhibitors (KIs; 80 KIs are not used clinically and 11 are FDA-approved KIs) on human CYPs-CYP1A2, 2C9, 2D6, and 3A4-were determined. For the majority of the KIs under analysis, a differential inhibitory effect on CYP enzymes was observed; fifteen compounds exhibited a potent inhibitory effect on CYP activities $\left(\mathrm{IC}_{50} \leq 1 \mu \mathrm{M}\right)$. Clinically used KIs-nilotinib, sunitinib, and imatinib-appeared to be potent CYP1A2 inhibitors with $\mathrm{IC}_{50}$ values of $0.92-1.23 \mu \mathrm{M}$ [79]. In the docking validation studies, 20 compounds among 22 inhibitors selected in highthroughput in vitro studies (90.9\%) demonstrated a high docking interaction energy. Three functional residues (Phe226, Phe125, and Asp320) in the active site of CYP1A2 were identified [79].

\section{The Site of Metabolism}

Identifying the sites of metabolism (SOMs) can play a decisive role in the design of drugs displaying desirable properties. The basic computational methods used for predicting SOMs and the structures of metabolites are QSAR, 3D QSAR, the pharmacophore-based method, molecular docking, molecular dynamics simulation, and a combined approach which is applied in numerous studies $[118,119]$. Computational techniques used in studies of xenobiotic metabolism are classified into the ligand-based approach and the structurebased approach. Taking into account the scope and limitations of these techniques, the combination of both ligand-based and structure-based approaches seems to be promising. In order to predict the site of metabolism, a molecular docking of substrates to the binding sites of cytochromes P450 may be performed. Lewis et al. [116] used CYP1A1 and CYP1A2 homology structures based on the CYP2C5 crystallographic template in a study of coumarin metabolism, finding a good correlation for binding energies determined experimentally and with the use of molecular docking.

In studies of stilbene derivatives, the molecular docking of $4^{\prime}$-methylthio-trans-stilbene derivatives to the CYP1A2 binding site confirmed the orientation of the $4^{\prime}$-methylthiophenyl ring of 2,4,5-trimethoxy-4'-methylthio-transstilbene and 3,4,5-trimethoxy-4'-methylthio-trans-stilbene in the close vicinity of the heme, allowing the reaction of hydroxylation at $\mathrm{C}-3^{\prime}$ to take place [77].

From all the binding modes obtained as a result of the docking procedure, possible metabolic sites of a substrate are assigned to the atoms located within $5 \AA$ from the Fe atom [120]. Molecular docking takes into account binding affinities and steric effects related to the conformation of an active site. The best results of SOM prediction were obtained with the approach combining molecular docking with semiempirical molecular orbital calculations that provide the activation energy characterizing the reactivity 
of a substrate [67]. Possible binding modes of CYP1A2 substrates were analyzed using automated docking with the use of the crystal structure of CYP1A2. For caffeine and theophylline, the SOMs found were in accordance with experimental data typing $\mathrm{N} 1-\mathrm{CH}_{3}, \mathrm{~N} 7-\mathrm{CH}_{3}$, and N3- $\mathrm{CH}_{3}$ as sites of the formation of primary and secondary metabolites [67].

Biotransformation studies of drugs can be performed with the use of molecular docking and molecular dynamics. Prediction of the formation of toxic metabolites is particularly important [121]. Two acetylcholinesterase inhibitors, derivatives of $p$-aminophenol and succinic anhydride, were tested in order to determine whether toxic metabolites are generated as in the case of $N$-acetyl-p-aminophenol (APAP) which is metabolized by CYP1A1 and CYP2B1 to toxic $N$-acetyl- $N$-hydroxy- $p$-aminophenol. Molecular dynamics confirmed that the amide group of APAP interacted with the heme iron of CYP1A1, and as a result of $\mathrm{N}$-oxidation, a toxic intermediate ( $N$-acetyl-p-benzoquinone imine) was formed. For both studied inhibitors docked to CYP1A1, this kind of interaction was not found. Instead, an aryl hydroxyl hydrogen interaction with the heme was observed. The results obtained in silico correlated well with the studies in vitro, which revealed the formation of only hydroxylated metabolites as a result of the metabolism of the studied inhibitors by rat liver microsomes [121]. The regioselectivity of APAP metabolism was studied with molecular docking and molecular dynamics, followed by 2D USP free energy scanning. CYP1A2 and CYP2E1, the enzymes with compact active sites, were found to be major APAP metabolizers [80]. APAP formed more interactions in CYP1A2 and CYP2E1 binding sites as compared with the more voluminous binding sites of CYP3A4 and CYP2C9, which resulted in stabilized binding states and a longer residence time.

\section{Conclusions}

Computational docking studies contribute to a better understanding of ligand-enzyme interactions at a molecular level. Studies with the use of computational procedures provide a rationalization of the selectivity of ligands toward CYP1 isozymes. The elucidation of cytochrome P450 family 1 -specific activities at a molecular level is of great importance with regard to novel and potent drug design and drug-drug interactions. Although computational methods have been significantly developed, a further improvement of virtual procedures could have an impact on their usefulness in the design of drugs targeting CYP enzymes by predicting the site of metabolism and drug-drug interactions and determining the potential toxicity of substrates and their metabolites.

Molecular docking helped to visualize spatial ligand fitting and molecular interactions occurring in the enzyme active site. The hypothesis is that not a single substituent but a pattern of substituents determines the shape of a molecule and influences a ligand's affinity to a binding site. The pattern of substituents exerts an effect on the ligand orientation in the enzyme active site, which in the case of some ligands is stabilized by hydrophobic interactions, especially $\pi-\pi$ stacking interactions. In the case of ligands that are substrates of enzymatic reactions, the distance between a ligand and the prosthetic group is essential for the course of reaction. Combining experimental studies on enzymatic reactions with a computer analysis of ligand-active site interactions are expected to produce valuable results, useful in the design of molecules with a desired activity.

Summarizing the achievements of the reports reviewed, many authors emphasize the versatility and plasticity of CYPs. In silico methods in the studies of ligand-CYP isozyme interactions provide a predictive model based mainly on van der Waals interactions, whereas electrostatic interactions do not play a considerable role here. The ligand can change its conformation through adaptation to the shape of the enzyme active site. Analyses of the ligand shape revealed the essential role of shape complementarity to the cavity of the enzyme binding site. Amino acid residues and water molecules can form hydrogen bonds that stabilize the ligand-enzyme complex.

Computational structure-based ligand design is a promising technique which enables an efficient analysis of preclinical drug candidates. Docking may be used to provide information about the conformation of a bioactive ligand and its position in the binding site. Knowing the orientation of a ligand helps to predict the site of metabolism.

\section{Conflicts of Interest}

The authors declare that there are no conflicts of interest regarding the publication of this paper.

\section{Acknowledgments}

The study was supported by funding from the Poznan University of Medical Sciences (no. 502-01-03313427-08870) and by Nicolaus Copernicus University in Toruń (Collegium Medicum Fund no. DS-UPB-WF-411).

\section{References}

[1] L. Chen, J. K. Morrow, H. T. Tran, S. S. Phatak, L. Du-Cuny, and S. Zhang, "From laptop to benchtop to bedside: structure-based drug design on protein targets," Current Pharmaceutical Design, vol. 18, no. 9, pp. 1217-1239, 2012.

[2] Y.-C. Chen, "Beware of docking," Trends in Pharmacological Sciences, vol. 36, no. 2, pp. 78-95, 2015.

[3] V. Lounnas, T. Ritschel, J. Kelder, R. McGuire, R. P. Bywater, and N. Foloppe, "Current progress in structure-based rational drug design marks a new mind set in drug discovery," Computational and Structural Biotechnology Journal, vol. 5, no. 6, article e201302011, 2013.

[4] J. Mortier, C. Rakers, M. Bermudez, M. S. Murgueitio, S. Riniker, and G. Wolber, "The impact of molecular dynamics on drug design: applications for the characterization of ligand-macromolecule complexes," Drug Discovery Today, vol. 20, no. 6, pp. 686-702, 2015.

[5] B. Waszkowycz, D. E. Clark, and E. Gancia, "Outstanding challenges in protein-ligand docking and structure-based virtual screening," WIREs Computational Molecular Science, vol. 1, no. 2, pp. 229-259, 2011. 
[6] U. M. Zanger, K. Klein, M. Thomas et al., "Genetics, epigenetics, and regulation of drug-metabolizing cytochrome P450 enzymes," Clinical Pharmacology and Therapeutics, vol. 95, no. 3, pp. 258-261, 2014.

[7] D. W. Nebert, T. P. Dalton, A. B. Okey, and F. J. Gonzalez, "Role of aryl hydrocarbon receptor-mediated induction of the CYP1 enzymes in environmental toxicity and cancer," Journal of Biological Chemistry, vol. 279, no. 7, pp. 2384723850, 2004.

[8] S. Rendic and F. P. Guengerich, "Contributions of human enzymes in carcinogen metabolism," Chemical Research in Toxicology, vol. 25, no. 7, pp. 1316-1383, 2012.

[9] K. Gajjar, P. L. Martin-Hirsch, and F. L. Martin, "CYP1B1 and hormone-induced cancer," Cancer Letters, vol. 324, no. 1, pp. 13-30, 2012.

[10] J. D. Yager, "Endogenous estrogens are carcinogens through metabolic activation," JNCI Monographs, vol. 2000, no. 27, pp. $67-73,2000$.

[11] Y.-J. Kwon, H.-S. Baek, D.-J. Ye, S. Shin, D. Kim, and Y.-J. Chun, "CYP1B1 enhances cell proliferation and metastasis through induction of EMT and activation of Wnt/ $\beta$-catenin signalling via Sp1 upregulation," PLoS One, vol. 11, no. 3, Article ID e0151598, 2016.

[12] D. W. Nebert and D. W. Russell, "Clinical importance of the cytochromes P450," The Lancet, vol. 360, no. 9340, pp. 1155-1162, 2002.

[13] R. Santes-Palacios, D. Ornelas-Ayala, N. Cabañas et al., "Regulation of human cytochrome P4501A1 (hCYP1A1): a plausible target for chemoprevention," BioMed Research International, vol. 2016, Article ID 5341081, 17 pages, 2016.

[14] H. I. Swanson, V. C. O. Njar, Z. Yu et al., "Targeting drugmetabolizing enzymes for effective chemoprevention and chemotherapy," Drug Metabolism and Disposition, vol. 38, no. 4, pp. 539-544, 2010.

[15] R. Dutour and D. Poirier, "Inhibitors of cytochrome P450 (CYP) 1B1," European Journal of Medicinal Chemistry, vol. 135, pp. 296-306, 2017.

[16] J. Cui, Q. Meng, X. Zhang, Q. Cui, W. Zhou, and S. Li, "Design and synthesis of new $\alpha$-naphthoflavones as cytochrome P450 (CYP) 1B1 inhibitors to overcome docetaxelresistance associated with CYP1B1 overexpression," Journal of Medicinal Chemistry, vol. 58, no. 8, pp. 3534-3547, 2015.

[17] I. Bièche, C. Narjoz, T. Asselah et al., "Reverse transcriptase-PCR quantification of mRNA levels from cytochrome (CYP)1, CYP2 and CYP3 families in 22 different human tissues," Pharmacogenetics and Genomics, vol. 17, no. 9, pp. 731-742, 2007.

[18] S. Badal and R. Delgod, "Role of the modulation of CYP1A1 expression and activity in chemoprevention," Journal of Applied Toxicology, vol. 34, no. 7, pp. 743-753, 2014.

[19] R.-E. Go, K.-A. Hwang, and K.-C. Choi, "Cytochrome P450 1 family and cancers," Journal of Steroid Biochemistry and Molecular Biology, vol. 147, pp. 24-30, 2015.

[20] L. W. Wattenberg, "Chemoprophylaxis of carcinogenesis: a review," Cancer Research, vol. 26, no. 7, pp. 1520-1526, 1966.

[21] H. Takemura, H. Sakakibara, S. Yamazaki, and K. Shimoi, "Breast cancer and flavonoids-a role in prevention," Current Pharmaceutical Design, vol. 19, no. 34, pp. 6125-6132, 2013.

[22] D. F. V. Lewis and B. G. Lake, "Molecular modelling of CYP1A subfamily members based on an alignment with CYP102: rationalization of CYP1A substrate specificity in terms of active site amino acid residues," Xenobiotica, vol. 26, no. 7, pp. 723-753, 1996.

[23] D. F. V. Lewis, B. G. Lake, S. G. George et al., "Molecular modelling of CYP1 family enzymes CYP1A1, CYP1A2,
CYP1A6 and CYP1B1 based on sequence homology with CYP102," Toxicology, vol. 139, no. 1-2, pp. 53-79, 1999.

[24] D. F. V. Lewis, B. G. Lake, and M. Dickins, "Quantitative structure-activity relationships within a homologous series of 7-alkoxyresorufins exhibiting activity towards CYP1A and CYP2B enzymes: molecular modelling studies on key members of the resorufin series with CYP2C5-derived models of human CYP1A1, CYP1A2, CYP2B6 and CYP3A4," Xenobiotica, vol. 34, no. 6, pp. 501-513, 2004.

[25] A. A. Walsh, G. Szklarz, and E. E. Scott, "Human cytochrome P450 1A1 structure and utility in understanding drug and xenobiotic metabolism," Journal of Biological Chemistry, vol. 288, no. 18, pp. 12932-12943, 2013.

[26] S. Sansen, J. K. Yano, R. L. Reynald et al., "Adaptations for the oxidation of polycyclic aromatic hydrocarbons exhibited by the structure of human P450 1A2," Journal of Biological Chemistry, vol. 282, no. 19, pp. 14348-14355, 2007.

[27] A. Wang, U. Savas, C. D. Stout, and E. F. Johnson, "Structural characterization of the complex between a-naphthoflavone and human cytochrome P450 1B1," Journal of Biological Chemistry, vol. 286, no. 7, pp. 5736-5743, 2011.

[28] G. D. Szklarz and M. D. Paulsen, "Molecular modeling of cytochrome P450 1A1: enzyme-substrate interactions and substrate binding affinities," Journal of Biomolecular Structure and Dynamics, vol. 20, no. 2, pp. 155-162, 2002.

[29] M.-J. Don, D. F. V. Lewis, S.-Y. Wang, M.-V. Tsai, and Y.-F. Ueng, "Effect of structural modification on the inhibitory selectivity of rutaecarpine derivatives on human CYP1A1, CYP1A2 and CYP1B1," Bioorganic \& Medicinal Chemistry Letters, vol. 13, no. 15, pp. 2535-2538, 2003.

[30] D. Schwarz, P. Kisselev, S. S. Ericksen et al., "Arachidonic and eicosapentaenoic acid metabolism by human CYP1A1: highly stereoselective formation of $17(\mathrm{R}), 18(\mathrm{~S})$ epoxyeicosatetraenoic acid," Biochemical Pharmacology, vol. 67, no. 8, pp. 1445-1457, 2004.

[31] J. Liu, S. S. Ericksen, M. Sivaneri, D. Besspiata, C. W. Fisher, and G. D. Szklarz, "The effect of reciprocal active site mutations in human cytochromes P450 1A1 and CYP1A2 on alkoxyresorufin metabolism," Archives of Biochemistry and Biophysics, vol. 424, no. 1, pp. 33-43, 2004.

[32] F. Iori, R. da Fonseca, M. J. Ramos, and M. C. Menziani, "Theoretical quantitative structure-activity relationships of flavone ligands interacting with cytochrome P450 1A1 and 1A2 isozymes," Bioorganic \& Medicinal Chemistry, vol. 13, no. 14 , pp. 4366-4374, 2005.

[33] S. S. Ericksen and G. D. Szklarz, "Regiospecificity of human cytochrome P450 1A1-mediated oxidations: the role of steric effects," Journal of Biomolecular Structure and Dynamics, vol. 23, no. 3, pp. 243-256, 2005.

[34] B. C. Lewis, P. I. Mackenzie, and J. O. Miners, "Comparative homology modeling of human cytochrome P4501A1 (CYP1A1) and conformation of residues involved in 7ethoxyresorufin O-deethylation by site-directed mutagenesis and enzyme kinetic analysis," Archives of Biochemistry and Biophysics, vol. 468, no. 1, pp. 58-69, 2007.

[35] R. P. Kommadi, C. M. Turman, B. Moorthy, L. Wang, H. W. Strobel, and V. Ravindranath, "An alternatively sliced cytochrome P4501A1 in human brain fails to bioactivate polycyclic aromatic hydrocarbons to DNA-reactive metabolites," Journal of Neurochemistry, vol. 102, no. 3, pp. 867877, 2007.

[36] J.-C. Tseng, M.-J. Don, D. F. V. Lewis, S.-Y. Wang, and Y.-F. Ueng, "Inhibition of CYP1 by dehydrorutaecarpine and 
its methoxylated derivatives," Journal of Food and Drug Analysis, vol. 15, no. 4, pp. 480-487, 2007.

[37] J. C. Prasad, JV Goldstone, CJ Camacho, S. Vajda, and J. J. Stegeman, "Ensemble modeling of substrate binding to cytochromes P450: analysis of catalytic differences between CYP1A orthologs," Biochemistry, vol. 46, no. 10, pp. 2640 2654, 2007.

[38] A. T. Sangamwar, L. B. Labhsetwar, and S. V. Kuberkar, "Exploring CYP1A1 as anticancer target: homology modeling and in silico inhibitor design," Journal of Molecular Modeling, vol. 14, no. 11, pp. 1101-1109, 2008.

[39] J. Sridhar, P. Jin, J. Liu, M. Foroozesh, and C. L. Klein Stevens, "In silico studies of polyaromatic hydrocarbon inhibitors of cytochrome P450 enzymes 1A1, 1A2, 2A6, and 2B1," Chemical Research in Toxicology, vol. 23, no. 3, pp. 600-607, 2010.

[40] J. Pan, G.-Y. Liu, J. Cheng, X.-J. Chen, and X.-L. Ju, "CoMFA and molecular docking studies of benzoxazoles and benzothiazoles as CYP450 1A1 inhibitors," European Journal of Medicinal Chemistry, vol. 45, no. 3, pp. 967-972, 2010.

[41] T. Shimada, K. Tanaka, S. Takenaka et al., "Structurefunction relationships of inhibition of human cytochromes P450 1A1, 1A2, 1B1, 2C9, and 3A4 by 33 flavonoid derivatives," Chemical Research in Toxicology, vol. 23, no. 12, pp. 1921-1935, 2010.

[42] H. Takemura, T. Itoh, K. Yamamoto, H. Sakakibara, and K. Shimoi, "Selective inhibition of methoxyflavonoids on human CYP1B1 activity," Bioorganic \& Medicinal Chemistry, vol. 18, pp. 6310-6315, 2010.

[43] M. C. Rosales-Hernández, J. E. Mendieta-Wejebe, J. G. TrujilloFerrara, and J. Correa-Basurto, "Homology modeling and molecular dynamics of CYP1A1 and CYP2B1 to explore the metabolism of aryl derivatives by docking and experimental assays," European Journal of Medicinal Chemistry, vol. 45, no. 11, pp. 4845-4855, 2010.

[44] T. Itoh, H. Takemura, K. Shimoi, and K. Yamamoto, “A 3D model of CYP1B1 explains the dominant 4-hydroxylation of estradiol," Journal of Chemical Information and Modeling, vol. 50, no. 6, pp. 1173-1178, 2010.

[45] K. Yamazaki, M. Suzuki, T. Itoh et al., "Structural basis of species differences between human and experimental animal CYP1A1s in metabolism of 3,3',4,4',5-pentachlorobiphenyl," Journal of Biochemistry, vol. 149, no. 4, pp. 487-494, 2011.

[46] M. K. A. Khan, S. Akhtar, and J. M. Arif, "Homology modelling of CYP1A1, CYP1B1 and its subsequent molecular docking studies with resveratrol and its analogues using AutoDock Tools 4.0," Biochemical and Cellular Archives, vol. 11, pp. 49-55, 2011.

[47] V. P. Androutsopoulos, A. Papakyriakou, D. Vourloumis, and D. A. Spandido, "Comparative CYP1A1 and CYP1B1 substrate and inhibitor profile of dietary flavonoids," Bioorganic \& Medicinal Chemistry, vol. 19, no. 9, pp. 2842-2849, 2011.

[48] J. Sridhar, J. Ellis, P. Dupart, J. Liu, C. L. Stevens, and M. Foroozesh, "Development of flavone propargyl ethers as potent and selective inhibitors of cytochrome enzymes CYP1A1 and CYP1A2," Drug Metabolism Letters, vol. 6, no. 4, pp. 275-284, 2012.

[49] Q. Huang, R. S. Deshmukh, S. S. Ericksen, Y. Tu, and G. D. Szklarz, "Preferred binding orientations of phenacetin in CYP1A1 and CYP1A2 are associated with isoformselective metabolism," Drug Metabolism and Disposition, vol. 40, no. 12, pp. 2324-2331, 2012.

[50] J. Gonzales, N. Marchand-Geneste, J. L. Giraudel, and T. Shimada, "Docking and QSAR comparative studies of polycyclic aromatic hydrocarbons and other procarcinogen interactions with cytochromes P450 1A1 and 1B1," SAR and QSAR in Environmental Research, vol. 23, no. 1-2, pp. 87-109, 2012.

[51] F. Yang, S. Zhuang, C. Zhang, H. Dai, and W. Liu, "Sulforaphane inhibits CYP1A1 activity and promotes genotoxicity induced by 2,3,7,8-tetrachlorodibenzo-p-dioxin in vitro," Toxicology and Applied Pharmacology, vol. 269, no. 3, pp. 226-232, 2013.

[52] P. P. Nandekar, K. M. Tumbi, N. Bansal et al., "Chembioinformatics and in vitro approaches for candidate optimization: a case study of NSC745689 as a promising antitumor agent," Medicinal Chemistry Research, vol. 22, no. 8, pp. 3728-3742, 2013.

[53] J. Liu, S. F. Taylor, P. S. Dupart et al., "Pyranoflavones: a group of small-molecule probes for exploring the active site activities of cytochrome P450 enzymes 1A1, 1A2 and 1B1," Journal of Medicinal Chemistry, vol. 56, no. 10, pp. 40824092, 2013.

[54] N. Goyal, J. Liu, L. Lovings et al., "Ethynyl flavones, highly potent, and selective inhibitors of CYP1A1," Chemical Research in Toxicology, vol. 27, no. 8, pp. 1431-1439, 2014.

[55] H. Inui, T. Itoh, K. Yamamoto, S.-I. Ikushiro, and T. Sakaki, "Mammalian cytochrome P-450-dependent metabolism of polychlorinated dibenzo- $p$-dioxins and coplanar polychlorinated biphenyls," International Journal of Molecular Sciences, vol. 15, no. 8, pp. 14044-14057, 2014.

[56] R. Mikstacka, M. Wierzchowski, Z. Dutkiewicz et al., " $3,4,2^{\prime}$ Trimethoxy-trans-stilbene-a potent CYP1B1 inhibitor," Medicinal Chemistry Communications, vol. 5, no. 4, pp. 496-501, 2014.

[57] P. Pragyan, S. S. Kesharwani, P. P. Nandekar, V. Rathod, and A. T. Sangamwar, "Predicting drug metabolism by CYP1A1, CYP1A2, and CYP1B1: insights from MetaSite, molecular docking and quantum chemical calculations," Molecular Diversity, vol. 18, no. 4, pp. 865-878, 2014.

[58] P. Urban, G. Truan, and D. Pompon, "Access channels to the buried active site control substrate specificity in CYP1 P450 enzymes," Biochimica et Biophysica Acta, vol. 1850, no. 4, pp. 696-707, 2015.

[59] H. Iwata, K. Yamaguchi, Y. Takeshita et al., "Enzymatic characterization of in vitro-expressed Baikal seal cytochrome P450 (CYP) 1A1, 1A2, and 1B1: implication of low metabolic potential of CYP1A2 uniquely evolved in aquatic mammals," Aquatic Toxicology, vol. 162, pp. 138-151, 2015.

[60] S. S. Kesharwani, P. P. Nandekar, P. Pragyan, V. Rathod, and A. T. Sangamwar, "Characterization of differences in substrate specificity among CYP1A1, CYP1A2 and CYP1B1: an integrated approach employing molecular docking and molecular dynamics simulations," Journal of Molecular Recognition, vol. 29, no. 8, pp. 370-390, 2016.

[61] R. Santes-Palacios, A. Romo-Mancillas, R. Camacho-Carranza, and J. J. Espinosa-Aguirre, "Inhibition of human and rat CYP1A1 enzyme by grapefruit juice compounds," Toxicology Letters, vol. 258, pp. 267-275, 2016.

[62] P. P. Nandekar, K. Khomane, V. Chaudhary et al., "Identification of leads for antiproliferative activity on MDA-MB435 human breast cancer cells through pharmacophore and CYP1A1-mediated metabolism," European Journal of Medicinal Chemistry, vol. 115, pp. 82-93, 2016.

[63] M. Wierzchowski, Z. Dutkiewicz, A. Gielara-Korzańska et al., "Synthesis, biological evaluation and docking studies of trans-stilbene methylthio derivatives as cytochromes P450 family 1 inhibitors," Chemical Biology \& Drug Design, vol. 90, no. 6, pp. 1226-1236, 2017. 
[64] J. J. Lozano, E. López-de-Briňas, N. B. Centeno, R. Guigó, and F. Sanz, "Three-dimensional modelling of human cytochrome P450 1A2 and its interaction with caffeine and MeIQ," Journal of Computer-Aided Molecular Design, vol. 11, no. 4, pp. 395-408, 1997.

[65] F. De Rienzo, F. Fanelli, C. Menziani, and P. G. De Benedetti, "Theoretical investigation of substrate specificity for cytochrome P450 IA2, P450 IID6 and P450 IIIA4," Journal of ComputerAided Molecular Design, vol. 14, no. 1, pp. 93-116, 2000.

[66] D. F. V. Lewis, "Modelling human cytochromes P450 involved in drug metabolism from the CYP2C5 crystallographic template," Journal of Inorganic Biochemistry, vol. 91, no. 4, pp. 502-514, 2002.

[67] J. Jung, N. D. Kim, S. Y. Kim et al., "Regioselectivity prediction of CYP1A2-mediated phase I metabolism," Journal of Chemical Information and Modeling, vol. 48, no. 5, pp. 1074-1080, 2008.

[68] Y. Tu, R. Deshmukh, M. Sivane, and G. D. Szklarz, “Application of molecular modeling for prediction of substrate specificity in cytochrome P450 1A2," Drug Metabolism and Disposition, vol. 36, no. 11, pp. 2371-2380, 2008.

[69] P. Vasanthanathan, J. Hritz, O. Taboureau et al., "Virtual screening and prediction of site of metabolism for cytochrome P450 1A2 ligands," Journal of Chemical Information and Modeling, vol. 49, no. 1, pp. 43-52, 2009.

[70] P. Vasanthanathan, L. Olsen, F. S. Jørgensen, N. P. E. Vermeulen, and C. Oostenbrink, "Computational prediction of binding affinity for CYP1A2-ligand complexes using empirical free energy calculation," Drug Metabolism and Disposition, vol. 38, no. 8, pp. 1347-1354, 2010.

[71] L. He, F. He, H. Bi et al., "Isoform-selective inhibition of chrysin towards human cytochrome P450 1A2. Kinetics analysis, molecular docking, and molecular dynamics simulations," Bioorganic \& Medicinal Chemistry Letters, vol. 20, no. 20, pp. 6008-6012, 2010.

[72] M. Huang and G. Szklarz, "Significant increase in phenacetin oxidation on L382V substitution in human cytochrome P450 1A2," Drug Metabolism and Disposition, vol. 38, no. 7, pp. 1039-1045, 2010.

[73] R. Zhu, L. Hu, H. Li, J. Su, Z. Cao, and W. Zhang, "Novel natural inhibitors of CYP1A2 identified by in silico and in vitro screening," International Journal of Molecular Sciences, vol. 12, no. 5, pp. 3250-3262, 2011.

[74] T. Hendrychová, E. Anzenbacherowá, J. Hudečzek et al., "Flexibility of human cytochrome P450 enzymes: molecular dynamics and spectroscopy reveal important functionrelated variations," Biochimica et Biophysica Acta, vol. 1814, no. 1, pp. 58-68, 2011.

[75] Y. J. Chun, C. Lim, S. O. Ohk et al., "trans-Stilbenoids: potent and selective inhibitors for human cytochrome P450 1B1," Medicinal Chemistry Communications, vol. 2, no. 5, pp. 402-405, 2011.

[76] Y.-X. Shao, P. Zhao, Z. Li et al., "The molecular basis for the inhibition of human cytochrome P450 1A2 by oroxylin and wogonin," European Biophysics Journal, vol. 41, no. 17, pp. 297-306, 2012.

[77] R. Mikstacka, A. M. Rimando, Z. Dutkiewicz, T. Stefański, and S. Sobiak, "Design, synthesis and evaluation of the inhibitory selectivity of novel trans-resveratrol analogues on human recombinant CYP1A1, CYP1A2 and CYP1B1," Bioorganic \& Medicinal Chemistry, vol. 20, no. 17, pp. 5117-5126, 2012.

[78] T. Zhang, L. A. Liu, D. F. V. Lewis, and D.-Q. Wei, "Longrange effects of a peripheral mutation on the enzymatic activity of cytochrome P4501A2," Journal of Chemical Information and Modeling, vol. 51, no. 6, pp. 1336-1346, 2011.

[79] Z.-X. Wang, J. Sun, C. E. Howell et al., "Prediction of the likelihood of drug interactions with kinase inhibitors based on in vitro and computational studies," Fundamental and Clinical Pharmacology, vol. 28, no. 5, pp. 551-582, 2014.

[80] Y. Yang, S. E. Wong, and F. C. Lightstone, "Understanding a substrate's product regioselectivity in a family of enzymes: a case study of acetaminophen binding in cytochrome P450s," PLoS One, vol. 9, no. 2, Article ID e87058, 2014.

[81] Y. Watanabe, S. Fukuyoshi, M. Hiratsuka et al., "Prediction of three-dimensional structures and structural flexibilities of wild-type and mutant cytochrome P450 1A2 using molecular dynamics simulations," Journal of Molecular Graphics \& Modelling, vol. 68, pp. 48-56, 2016.

[82] D. F. V. Lewis, E. M. J. Gillam, S. A. Everett, and T. Shimada, "Molecular modelling of human CYP1B1 substrate interactions and investigation of allelic variant effects on metabolism," Chemico-Biological Interactions, vol. 145, no. 3, pp. 281-295, 2003.

[83] M. S. Achary and H. A. Nagarajaram, "Comparative docking studies of CYP1b1 and its PCG-associated mutant forms," Journal of Biosciences, vol. 33, no. 5, pp. 699-713, 2008.

[84] P. A. Williams, J. Cosme, V. Sridhar, P. F. Johnson, and D. E. McRee, "Mammalian microsomal cytochrome P450 monooxygenase: structural adaptations for membrane binding and functional diversity," Molecular Cell, vol. 5, no. 1, pp. 121-131, 2000.

[85] B. Wang and S.-F. Zhou, "Synthetic and natural compounds that interact with human cytochrome P450 1A2 and implications in drug development," Current Medicinal Chemistry, vol. 16, no. 31, pp. 4066-4218, 2009.

[86] P. Vasanthanathan, O. Taboureau, C. Oostenbrink, N. P. E. Vermeulen, L. Olsen, and F. S. Jørgensen, "Classification of cytochrome P450 1A2 inhibitors and noninhibitors by machine learning techniques," Drug Metabolism and Disposition, vol. 37, no. 3, pp. 658-664, 2009.

[87] Y. Watanabe, S. Fukuyoshi, K. Kato et al., "Investigation of substrate recognition for cytochrome P450 1A2 mediated by water molecules using docking and molecular dynamics simulations," Journal of Molecular Graphics \& Modelling, vol. 74, pp. 326-336, 2017.

[88] J. Liu, P. T. Pham, E. V. Skripnikova et al., "A ligand-based drug design. Discovery of 4-trifluoromethyl-7,8-pyranocoumarin as a selective inhibitor of human cytochrome P450 1A2," Journal of Medicinal Chemistry, vol. 58, no. 16, pp. 6481-6493, 2015.

[89] O. Gotoh, "Substrate recognition sites in cytochrome P450 family 2 (CYP2) proteins inferred from comparative analyses of amino acid and coding nucleotide sequences," Journal of Biological Chemistry, vol. 267, no. 1, pp. 83-90, 1992.

[90] M. Ito, Y. Katono, A. Oda, N. Hirasawa, and M. Hiratsuka, "Functional characterization of 20 allelic variants of CYP1A2," Drug Metabolism and Pharmacokinetics, vol. 30, no. 3, pp. 247-252, 2015.

[91] L.-N. Ma, Z.-Z. Du, P. Lian, and D.-Q. Wei, “A theoretical study on the mechanism of a superficial mutation inhibiting the enzymatic activity of CYP1A2," Interdisciplinary Sciences, vol. 6, no. 1, pp. 25-31, 2014.

[92] V. Cojocaru, P. J. Winn, and R. C. Wade, "The ins and outs of cytochrome P450s," Biochimica et Biophysica Acta, vol. 1770, no. 3, pp. 390-401, 2007.

[93] T. Shimada, J. Watanabe, K. Inoue, F. P. Guengerich, and E. M. J. Gillam, "Specificity of $17 \beta$-oestradiol and benzo[a] 
pyrene oxidation by polymorphic human cytochrome P4501B1 variants substituted at residues 48, 119 and 432," Xenobiotica, vol. 31, no. 3, pp. 163-176, 2001.

[94] I. Jansson, I. Stoilov, M. Sarfarazi, and J. B. Schenkman, "Effects of two mutations on cytochrome P4501B1 G61E and R469W, on stability and endogenous steroid metabolism," Pharmacogenetics, vol. 11, no. 9, pp. 793-801, 2001.

[95] N. Moitessier, P. Englebienne, D. Lee, J. Lawandi, and C. R. Corbeil, "Towards the development of universal, fast and highly accurate docking/scoring methods: a long way to go," British Journal of Pharmacology, vol. 153, no. S1, pp. S7-S26, 2008.

[96] F. Feixas, S. Lindert, W. Sinko, and J. A. McCammon, "Exploring the role of receptor flexibility in structure-based drug discovery," Biophysical Chemistry, vol. 186, pp. 31-45, 2014.

[97] D. A. Antunes, D. Devaurs, and L. E. Kavraki, "Understanding the challenges of protein flexibility in drug design," Expert Opinion on Drug Discovery, vol. 10, no. 12, pp. 1301-1313, 2015.

[98] E. Yuriev, J. Holien, and P. A. Ramsland, "Improvements, trends, and new ideas in molecular docking: 2012-2013 in review," Journal of Molecular Recognition, vol. 28, no. 10, pp. 581-604, 2015.

[99] A. Ganesan, M. L. Coote, and K. Barakat, "Molecular dynamics-driven drug discovery: leaping forward with confidence," Drug Discovery Today, vol. 22, no. 2, pp. 249$269,2017$.

[100] P. Vasanthanathan, J. Lastdrager, C. Oostenbrink et al., "Identification of CYP1A2 ligands by structure-based and ligand-based virtual screening," Medicinal Chemistry Communications, vol. 2, no. 9, pp. 853-859, 2011.

[101] B. T. Zhu and A. J. Lee, "NADPH-dependent metabolism of $17 \beta$-estradiol and estrone to polar and nonpolar metabolites by human tissues and cytochrome P450 isoforms," Steroids, vol. 70, no. 4, pp. 225-244, 2005.

[102] Y. Tsuchiya, M. Nakajima, and T. Yokoi, "Cytochrome $\mathrm{P} 450$-mediated metabolism of estrogens and its regulation in human," Cancer Letters, vol. 227, no. 2, pp. 115-124, 2005.

[103] F. F. Parl, S. Dawling, N. Roodi, and P. S. Crooke, "Estrogen metabolism and breast cancer: a risk model," Annals of the New York Academy of Sciences, vol. 1155, no. 1, pp. 68-75, 2009.

[104] T. Shimada, N. Murayama, K. Tanaka et al., "Interaction of polycyclic aromatic hydrocarbons with human cytochrome P450 1B1 in inhibiting catalytic activity," Chemical Research in Toxicology, vol. 21, no. 12, pp. 2313-2323, 2008.

[105] J. A. Sirerol, M. L. Rodriguez, S. Mena, M. A. Asensi, J. M. Estrela, and A. L. Ortega, "Role of natural stilbenes in the prevention of cancer," Oxidative Medicine and Cellular Longevity, vol. 2016, Article ID 3128951, 15 pages, 2016.

[106] J. K. Kundu and Y.-J. Surh, "Cancer chemopreventive and therapeutic potential of resveratrol: mechanistic perspectives," Cancer Letters, vol. 269, no. 2, pp. 243-261, 2008.

[107] M. E. Juan, I. Alfaras, and J. M. Planas, "Colorectal cancer chemoprevention by trans-resveratrol," Pharmacological Research, vol. 65, no. 6, pp. 584-591, 2012.

[108] T. K. H. Chang, W. B. Lee, and H. H. Ko, “Trans-resveratrol modulates the catalytic activity and m-RNA expression of the procarcinogens-activating human cytochrome P450 1B1," Canadian Journal of Physiology and Pharmacology, vol. 78, no. 11, pp. 874-881, 2000.

[109] T. K. H. Chang, J. Chen, and W. B. K. Lee, "Differential inhibition and inactivation of human CYP1 enzymes by trans-resveratrol: evidence for mechanism-based inactivation of CYP1A2," Journal of Pharmacology and Experimental Therapeutics, vol. 299, no. 3, pp. 874-882, 2001.

[110] T. Walle, F. Hsieh, M. H. DeLegge, J. E. Oatis Jr., and U. K. Walle, "High absorption but very low bioavailability of oral resveratrol in humans," Drug Metabolism and Disposition, vol. 32, no. 12, pp. 1377-1382, 2004.

[111] R. Mikstacka, D. Przybylska, A. M. Rimando, and W. BaerDubowska, "Inhibition of human recombinant cytochromes P450 CYP1A1 and CYP1B1 by trans-resveratrol methyl ethers," Molecular Nutrition \& Food Research, vol. 51, no. 5, pp. 517-524, 2007.

[112] Y.-J. Chun, S. Y. Ryu, T. C. Jeong, and M. Y. Kim, "Mechanism-based inhibition of human cytochrome P450 1 A1 by rhapontigenin," Drug Metabolism and Disposition, vol. 29, no. 1, pp. 389-393, 2001.

[113] Y.-J. Chun, S. Kim, D. Kim, S. K. Lee, and F. P. Guengerich, "A new selective and potent inhibitor of human cytochrome P450 1B1 and its application to antimutagenesis," Cancer Research, vol. 61, no. 22, pp. 8164-8170, 2001.

[114] Y.-J. Chun, Y.-K. Oh, B. J. Kim et al., "Potent inhibition of human cytochrome P450 1B1 by tetramethoxystilbene," Toxicology Letters, vol. 189, no. 1, pp. 84-89, 2009.

[115] J. Liu, J. Sridhar, and M. Foroozesh, "Cytochrome P450 family 1 inhibitors and structure-activity relationships," Molecules, vol. 18, no. 12, pp. 14470-14495, 2013.

[116] D. F. V. Lewis, Y. Ito, and B. G. Lake, "Metabolism of coumarin by human P450s: a molecular modelling study," Toxicology in Vitro, vol. 20, no. 2, pp. 256-264, 2006.

[117] J. Sridhar, J. Liu, M. Foroozesh, and C. L. Klein Stevens, "Inhibition of cytochrome P450 enzymes by quinones and anthraquinones," Chemical Research in Toxicology, vol. 25, no. 2, pp. 357-365, 2012.

[118] J. Kirchmair, M. J. Williamson, J. D. Tyzack et al., "Computational prediction of metabolism: sites, products, SAR, P450 enzyme dynamics and mechanisms," Journal of Chemical Information and Modeling, vol. 52, no. 3, pp. 617-648, 2012.

[119] L. Olsen, C. Oostenbrink, and F. S. Jorgensen, "Prediction of cytochrome P450 mediated metabolism," Advanced Drug Delivery Reviews, vol. 86, pp. 61-71, 2015.

[120] C. de Graaf, C. Oostenbrink, P. H. Keizers, T. van der Wijst, A. Jongejan, and N. P. Vermeulen, "Catalytic site prediction and virtual screening of cytochrome P450 2D6 substrates by consideration of water and rescoring in automated docking," Journal of Medicinal Chemistry, vol. 49, no. 8, pp. 2417-2430, 2006.

[121] N. K. Mishra, "Computational modelling of P450s for toxicity prediction," Expert Opinion on Drug Metabolism \& Toxicology, vol. 7, no. 10, pp. 1211-1231, 2011. 

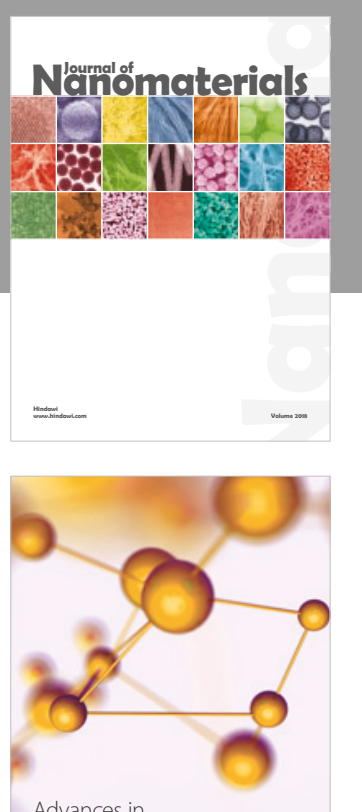

Physical Chemistry
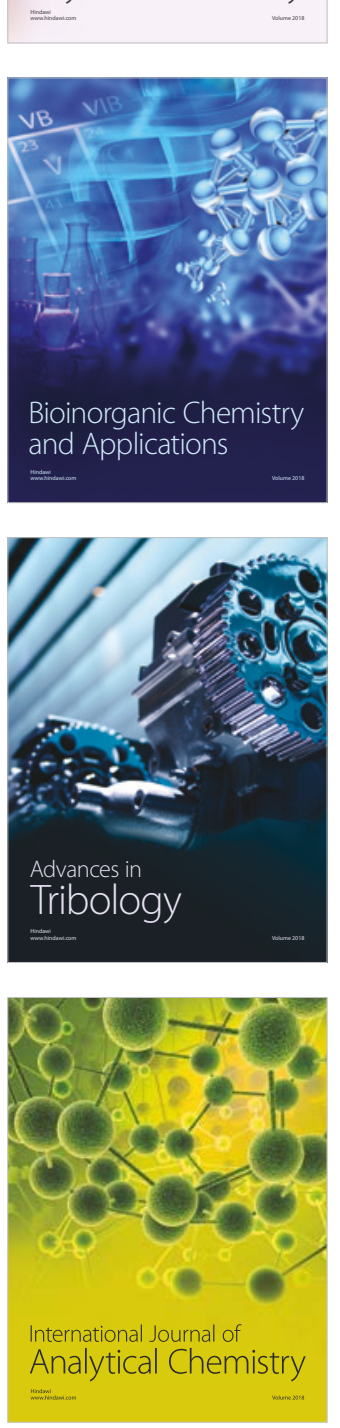

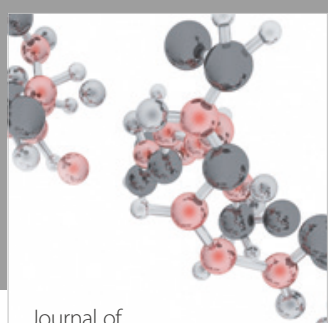

Analytical Methods

in Chemistry

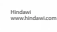

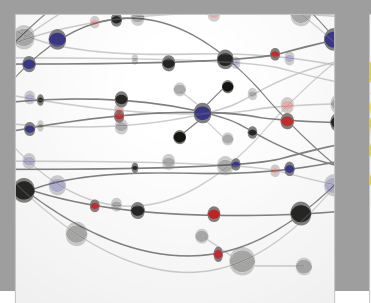

The Scientific World Journal

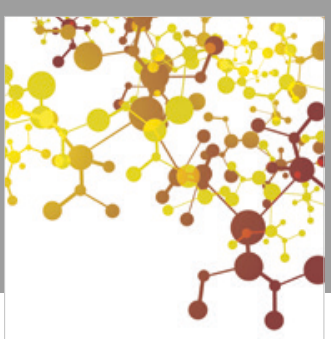

Journal of

Applied Chemistry
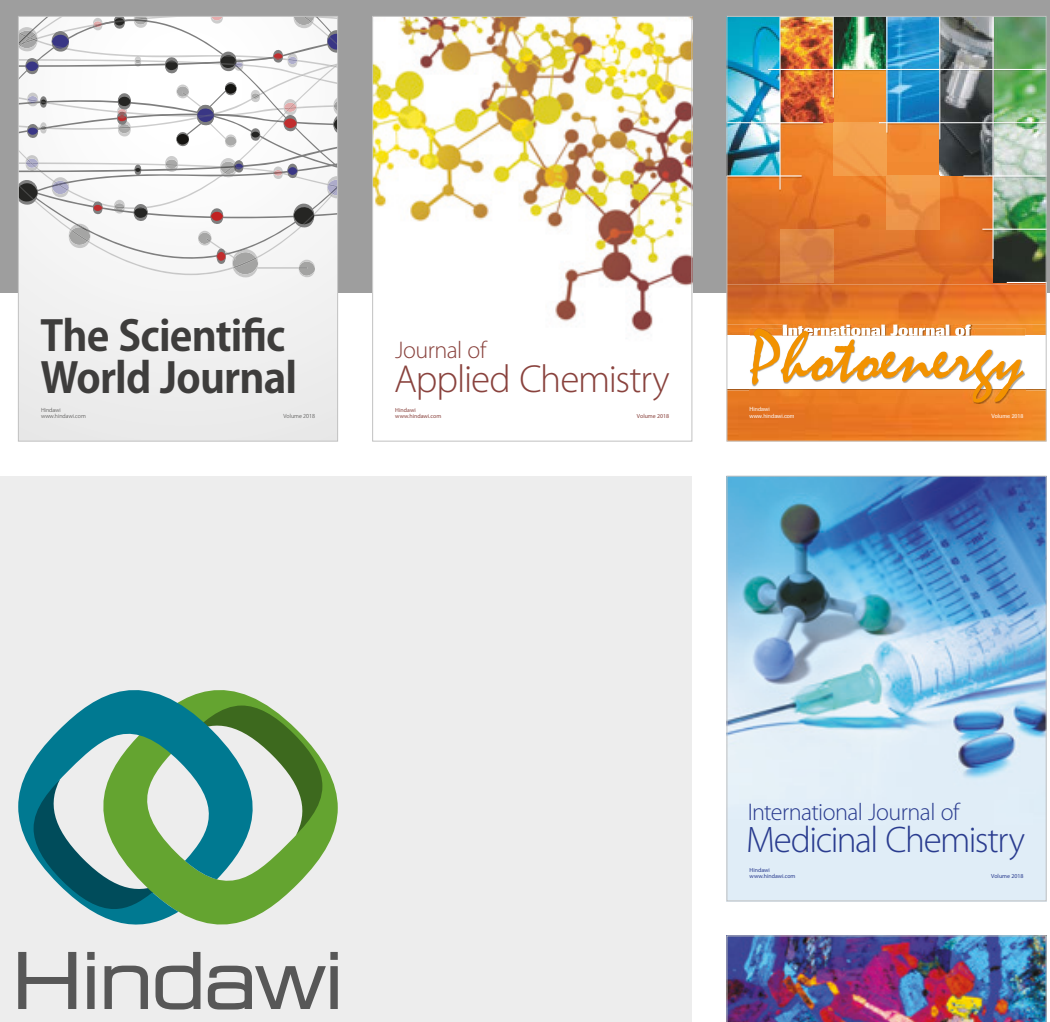

Submit your manuscripts at

www.hindawi.com
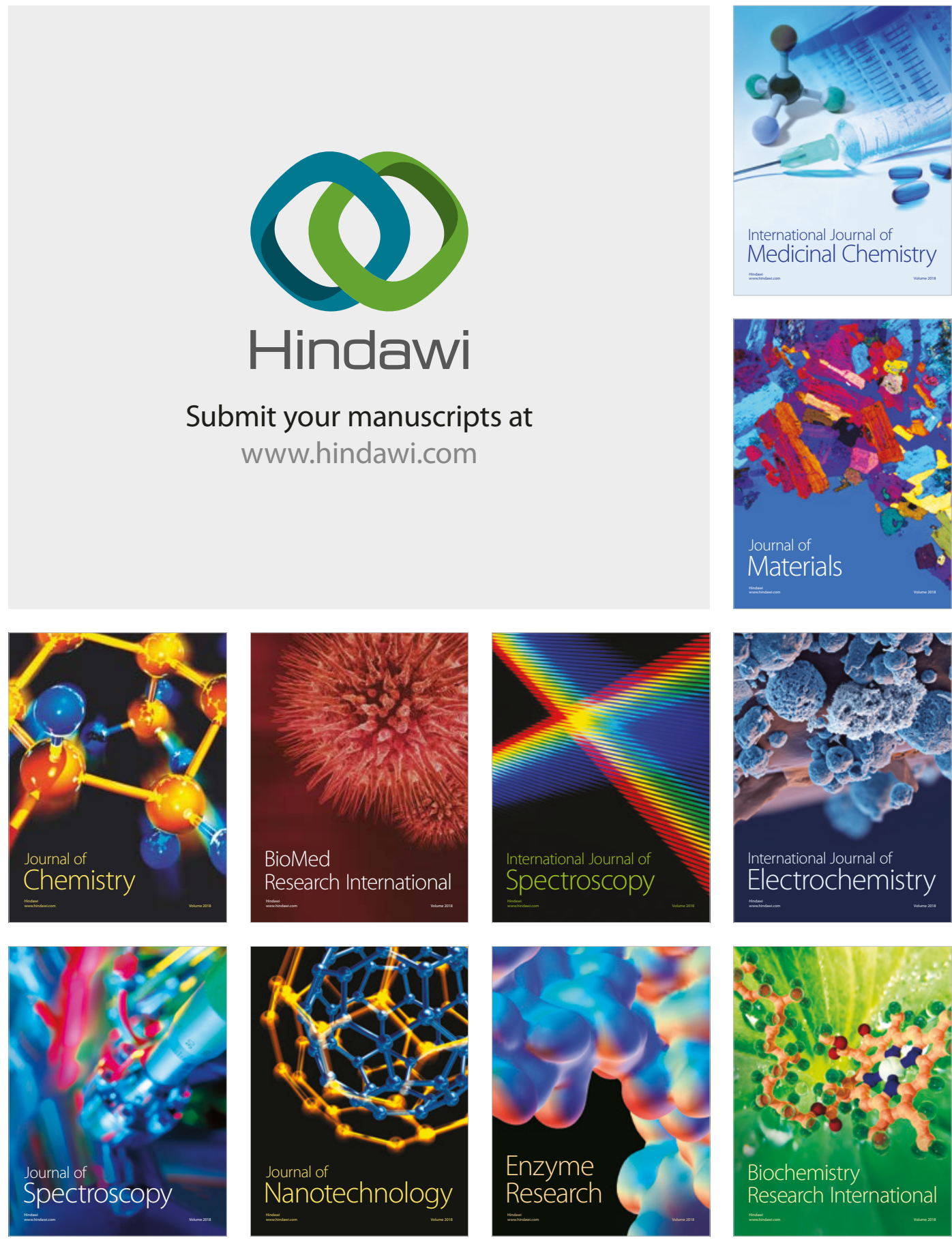
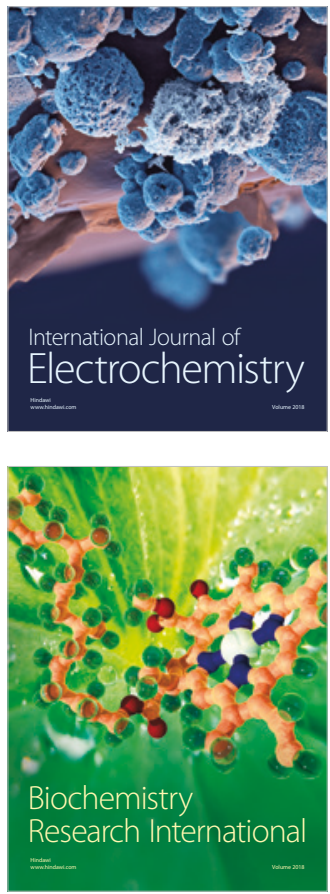